Article

\title{
ESA-MERIS 10-Year Mission Reveals Contrasting Phytoplankton Bloom Dynamics in Two Tropical Regions of Northern Australia
}

\author{
David Blondeau-Patissier ${ }^{1,2, *}$, Thomas Schroeder ${ }^{3}$, Vittorio E. Brando ${ }^{4}$, Stefan W. Maier ${ }^{2}$, \\ Arnold G. Dekker ${ }^{4}$ and Stuart Phinn ${ }^{5}$ \\ 1 North Australian Marine Research Alliance (NAMRA), Darwin 0909, Australia \\ 2 Research Institute for the Environment and Livelihoods (RIEL), Charles Darwin University, \\ Darwin 0909, Australia; E-Mail: stefan.maier@cdu.edu.au \\ 3 CSIRO Land and Water (CLW), Brisbane 4001, Australia; E-Mail: Thomas.Schroeder@csiro.au \\ 4 CSIRO Land and Water (CLW), Canberra 2601, Australia; \\ E-Mails: vittorio.brando@csiro.au (V.E.B.); Arnold.Dekker@csiro.au (A.G.D.) \\ 5 School of Geography, Planning and Environmental Management (GPEM), The University of \\ Queensland, Brisbane 4072, Australia; E-Mail: s.phinn@uq.edu.au \\ * Author to whom correspondence should be addressed; \\ E-Mail: David.BlondeauPatissier@cdu.edu.au; Tel.: +61-8-8946-6646; Fax: +61-8-8946-7720.
}

Received: 2 September 2013; in revised form: 4 March 2014 / Accepted: 19 March 2014 /

Published: 1 April 2014

\begin{abstract}
The spatial and temporal variability of phytoplankton blooms was investigated in two tropical coastal regions of northern Australia using the MEdium Resolution Imaging Spectrometer (MERIS) full mission (2002-2012) reduced resolution dataset. Satellite-derived proxies for phytoplankton (Chlorophyll-a (Chl), Fluorescence Line Height (FLH), Maximum Chlorophyll Index (MCI)) and suspended sediment (Total Suspended Matter (TSM)) were jointly analyzed for two clusters of the Great Barrier Reef Wet tropics (GBRW; $15^{\circ}-19.5^{\circ} \mathrm{S}$; Queensland) and the Van Diemen Gulf (VDG; $9^{\circ}-13^{\circ} \mathrm{S}$; Northern Territory). The analysis of time-series and Hovmöller diagrams of the four MERIS products provided a unique perspective on the processes linking phytoplankton blooms and river runoff, or resuspension, across spatio-temporal scales. Both regions are characterized by a complex oceanography and seasonal inflows of sediment, freshwater and nutrients during the tropical wet season months (November to April). The GBRW is characterized by a great variability in water clarity (Secchi depth 0-25 m). A long history of agricultural land use has led to a large increase in the seasonal discharge of sediments and nutrients, triggering
\end{abstract}


seasonal phytoplankton blooms $\left(>0.4 \mathrm{mg} \cdot \mathrm{m}^{-3}\right)$ between January and April. In contrast, the VDG is a poorly flushed, turbid (Secchi depth $<5 \mathrm{~m}$ ) environment with strong tidal-energy $(4-8 \mathrm{~m})$ and very limited land use. Phytoplankton blooms here were found to have higher Chl concentrations $\left(>1.0 \mathrm{mg} \cdot \mathrm{m}^{-3}\right)$ than in the GBRW, occurring up to twice a year between January and April. Over the 10-year MERIS mission, a weak decline in Chl and TSM was observed for the VDG (Sen slope: $-2.85 \% /$ decade, $\tau=-0.32$ and $-3.57 \% /$ decade, $\tau=-0.24 ; p \ll 0.05$ ), while no significant trend in those two satellite products was observed in the GBRW. Cyanobacteria surface algal blooms occur in both regions between August and October. The MCI and FLH products were found to adequately complement Chl, while TSM provided relevant insight for the assessment of sediment resuspension and river runoff.

Keywords: phytoplankton; spatio-temporal patterns; MERIS; FLH; MCI; Great Barrier Reef; Van Diemen Gulf; tropical waters; wet tropics

\section{Introduction}

Spatial and temporal mapping of phytoplankton blooms has been undertaken in many parts of the world's oceans, with a major emphasis on temperate coastal and oceanic waters where an annual spring bloom occurs [1,2]. Yet phytoplankton dynamics in tropical marine systems remains largely understudied. To address this knowledge gap, this study investigated the spatio-temporal distribution of phytoplankton blooms by means of satellite proxies in the context of the tropical waters of the Northern Great Barrier Reef (GBR, North Queensland) and the Van Diemen Gulf (VDG, Northern Territory), Australia. The coastal regions studied are Cairns $\left(15.1^{\circ}-19.5^{\circ} \mathrm{S}\right)$, located in the Great Barrier Reef Wet tropics (later referred as GBRW), and the VDG $\left(9^{\circ}-13^{\circ} \mathrm{S}\right)$. Both study regions are intricate, bio-diverse coastal ecosystems with a complex oceanography $[3,4]$.

Due to intensified anthropogenic pressures and potential climate change [5], tropical ecosystems are at risk worldwide [6]. The GBR is at the forefront of this situation [7], with watershed-based pollution from adjacent agricultural land use [8,9] and thermal stress affecting its coral ecosystem [10]. The GBRW has small $\left(\sim 2000 \mathrm{~km}^{2}\right)$, wet tropical river catchments. Seasonal river runoff from the Herbert, Johnstone, Tully and Daintree rivers (Figure 1a) carry pollutants, total suspended matter (TSM $\left.\sim 10 \mathrm{~g} \cdot \mathrm{m}^{-3} ;[11]\right)$ and elevated nutrient concentrations $[9,12]$ into the lagoonal waters. In contrast, the continental shelf of the Northern Territory is one of the most pristine coastal environments worldwide [13]. Its waters are highly productive [14], particularly when compared to the GBR. The VDG is a macro-tidal coastal system characterized by high concentrations of TSM $\left(\sim 20-50 \mathrm{~g} \cdot \mathrm{m}^{-3}\right)$ throughout the year. The rivers' hydrological regime of the two study regions is dictated by the seasonal rainfall distribution. Both regions receive similar annual rainfall $\left(\sim 2000 \mathrm{~mm} \cdot \mathrm{yr}^{-1}\right.$; monthly climate statistics (1941-2010) from the Bureau of Meteorology (BOM), Australian Government), generally from January to April for the GBRW and from December to March for the VDG. The river stream discharges and their patterns vary considerably within seasons. The land cover in the GBRW catchment is mainly of wet tropical rainforest and cleared land where the major land use is agriculture 
(sugarcane, dairy, beef grazing) [3,8]. Catchments of varying sizes surround the VDG and they comprise five major river systems: the West, South $\left(10,000 \mathrm{~km}^{2}\right)$ and East Alligator, the Mary $\left(8000 \mathrm{~km}^{2}\right)$ and the Adelaide rivers $\left(638 \mathrm{~km}^{2}\right)$ (Figure $\left.1 \mathrm{~b}\right)$. The land use of those river catchments is primarily for conservation and low intensity farming activities.

Figure 1. Maps showing the two tropical study regions. (a) The Great Barrier Reef (Wet tropics), Queensland. Hinchinbrook Island is shown as "HI"; (b) the Van Diemen Gulf, Northern Territory. The main rivers are indicated in italic and light grey. Isobaths $(-10,-50,-100 \mathrm{~m})$ are shown.
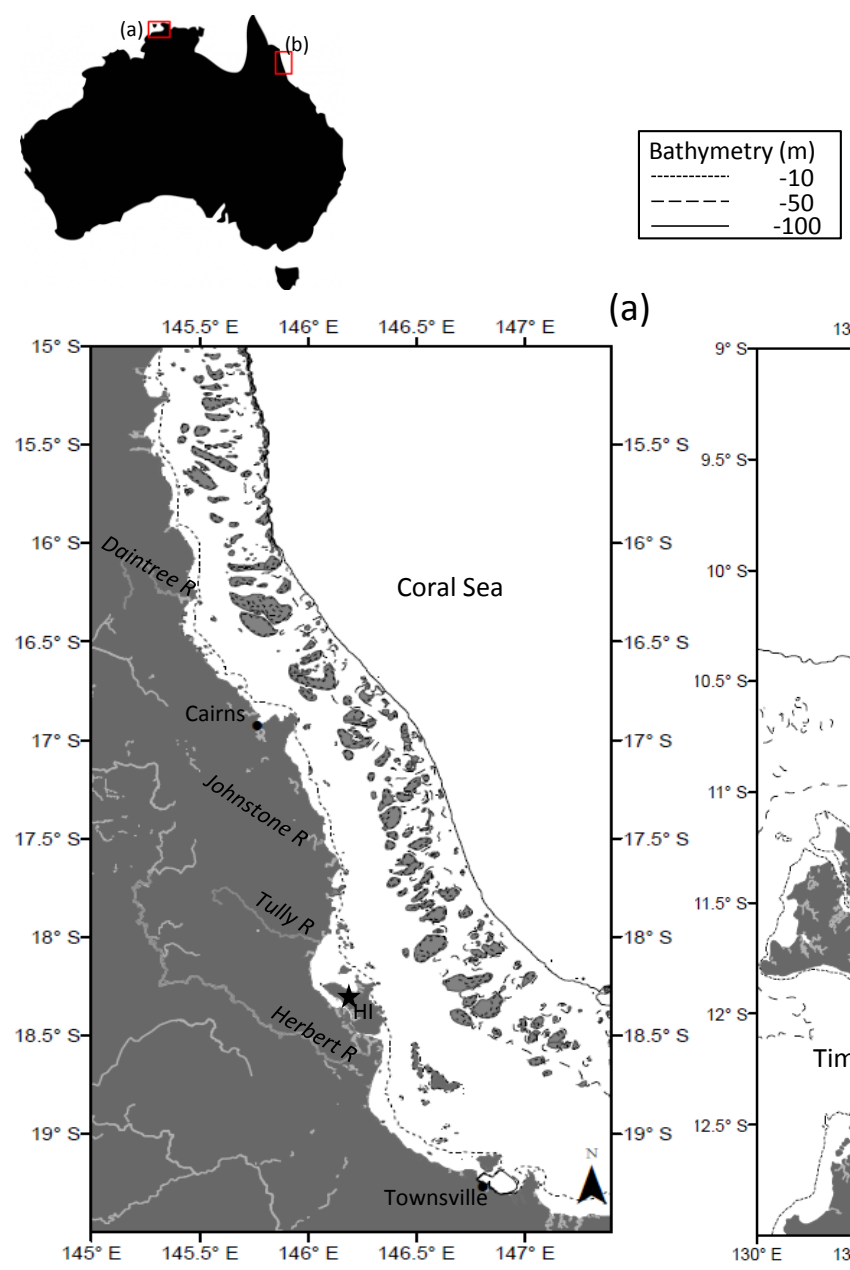

(a)

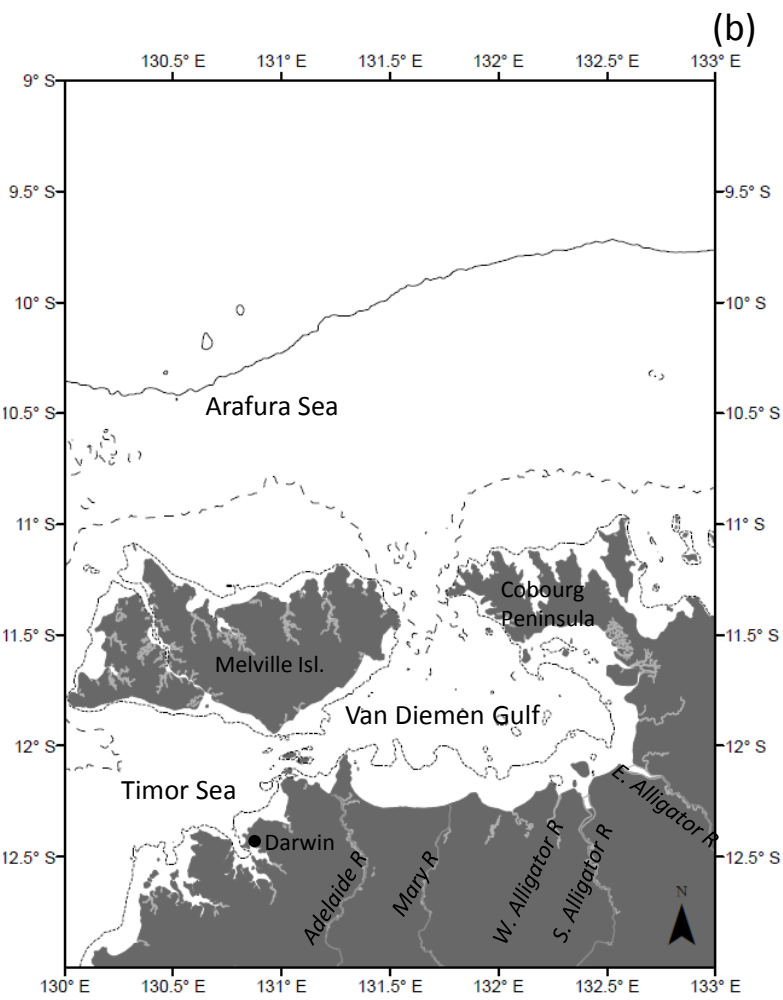

Since the launch of CZCS in the late seventies, satellite-derived Chlorophyll ( $\mathrm{Chl}$ ) has been used for several decades as the primary proxy for phytoplankton biomass. Due to the limited number of spectral bands, satellite products were derived from empirical spectral band ratios. The reliability of the satellite retrievals is questionable when dealing with coastal waters where other optically active substances, such as suspended sediment and organic matter, affect the reflectance spectrum [15]. The MEdium Resolution Imaging Spectrometer (MERIS), from the second generation of ocean color sensors, offers a much larger number of spectral bands, thus allowing various water quality products to be derived for both coastal and open ocean waters [16-22]. The combined analysis of multiple satellite products for the study of phytoplankton blooms allows for a more accurate description of the event and its causative environmental factors [23-26]. MERIS has provided satellite ocean color imagery 
between April 2002 and April 2012, and with 15 spectral bands this sensor is well suited for water quality monitoring in coastal waters [27]. For this study, four MERIS products, namely Chlorophyll (Chl) and Fluorescence Line Height (FLH), Maximum Chlorophyll Index (MCI) and Total Suspended Matter (TSM), were chosen as indicators of phytoplankton biomass, phytoplankton surface expressions and river discharges (or bottom resuspension) to assess phytoplankton bloom dynamics in the waters of the GBRW and the VDG (Figures 1 and 2). This study aims at demonstrating that the combined analysis of four ocean color products over the full mission of a single sensor can be used to unravel the dynamics of phytoplankton in a coastal region. Specifically, the objectives of this research are to qualitatively analyze the temporal and spatial patterns of phytoplankton blooms in selected clusters of the GBRW and the VDG.

\section{Data and Methods}

\subsection{Ocean Color Dataset and Algorithms}

Scenes (3rd reprocessing; $N=1980$; April 2002-April 2012) from the entire MERIS mission covering the VDG and GBRW were obtained from the Optical Data Processor of the European Space Agency (ODESA), supplied by ACRI-ST [28]. The two study regions are located in the Wet tropics where high levels of sun-glint and cloud cover are known to occur [29]. At latitudes $9-13^{\circ} \mathrm{S}$ (VDG) cloud cover is at its maximum early in the monsoon (December-February), contaminating up to 60\% of the pixels (based on daily scenes). Similar results were found for GBRW (15-19.5 $\mathrm{S}$ ). Monthly composites were computed for all the ocean color products to maximize the spatial and temporal coverage.

Detection of surface phytoplankton blooms was undertaken using the three MERIS products: FLH [30], MCI [31] and Chl [32]. A fourth ocean color product, TSM, was used as a proxy for river discharges and bottom resuspension. All MERIS ocean color products were computed from Level 1 with BEAM 4.10.3 [33]. Level 2 TSM and case 2 water Chl (algal 2) products were computed from Level 1 using the Free University Berlin (FUB) Water processor. The FUB Water processor retrieves the concentrations from a 1-step inversion neural network directly from top-of-atmosphere (TOA) radiance spectra [34]. Quality flags were applied to both Level 1 (MCI, FLH) and Level 2 (Chl, TSM) data. Additionally, Level 1 pixels with radiance $>15 \mathrm{~mW} \cdot \mathrm{m}^{-2} \cdot \mathrm{sr}^{-1} \cdot \mathrm{nm}^{-1}$ at band 13 that were not already flagged by Level 1 quality flags were eliminated [31].

In situ Chl concentrations were available for the GBR, and FUB Chl was found to perform reasonably well $\left(\mathrm{N}=12\right.$; RMS Error $=38 \%(\log )$; time diff. in situ-overpass $\left.=30^{\prime}\right)$ from a previous validation exercise [35]. However, the same validation showed that FUB TSM tended to underestimate in situ data $\left(\mathrm{N}=8\right.$; RMS Error $=110 \%(\log )$; time diff. in situ-overpass $\left.=30^{\prime}\right)$ and a larger dataset would be required to perform this validation adequately. Due to the remoteness of the VDG, the lack of in situ data did not allow for any validation of the MERIS products to be performed. Therefore this study will solely reflect the qualitative use of the MERIS products rather than their quantitative estimates. The FLH and MCI are two MERIS phytoplankton bloom proxies that use three MERIS spectral bands from the red and near-infrared [26]. FLH measures the radiance of the phytoplankton chlorophyll fluorescence peak at $681 \mathrm{~nm}$ above a baseline formed by linear interpolation between 665 
and $709 \mathrm{~nm}$. MCI, however, uses $709 \mathrm{~nm}$ as the response band above a linear baseline between 681 and $753 \mathrm{~nm}$. MCI detects either an isolated peak at $709 \mathrm{~nm}$, indicating $\mathrm{Chl}>30 \mathrm{mg} \cdot \mathrm{m}^{3}$ in near-surface water, or a red edge indicating a surface slick. The MCI is used here as an index for phytoplankton blooms with surface expressions formed by senescent cyanobacterium Trichodesmium sp. (Figure 2c). Both indices have been successfully used to measure near-surface phytoplankton biomass in coastal and freshwater environments [36-39]. FLH and MCI were computed from Level 1b TOA satellite data (therefore geolocated, but not atmospherically corrected). Although other applications exist for MERIS MCI [40], it has been shown to perform well for mapping phytoplankton blooms with surface expressions [35] however this index alone is not sufficient to confirm the phytoplankton genus. MERIS FLH is mostly suited for low-concentration ( $\mathrm{Chl}<5 \mathrm{mg} \cdot \mathrm{m}^{-3}$ ) phytoplankton blooms. FLH can also be used for the detection of phytoplankton in sediment-dominated waters [38] when TSM $<1 \mathrm{~g} \cdot \mathrm{m}^{-3}$ (Jim Gower, Fisheries and Oceans Canada, pers. com.). Monthly positive MCI or FLH counts (the number of times a pixel has a value of MCI (or FLH) $>0$ over the course of a month) were also used to quantify algal bloom statistics.

Figure 2. MEdium Resolution Imaging Spectrometer (MERIS) scene of 30 July 2008 for the Great Barrier Reef Wet tropics (GBRW), illustrating the potential of multiple MERIS products for algal blooms monitoring. A surface bloom occurs near Hinchinbrook Isl. $\left(18.5^{\circ} \mathrm{S}\right.$; black star in (a)). The four MERIS products used for this study are shown. (a) RGB BEAM Tristimulus; (b) a band stretched image with MERIS bands 10, 7, 5; (c) Maximum Chlorophyll Index (MCI); (d) Fluorescence Line Height (FLH); (e) Free University Berlin (FUB) Chlorophyll-a (Chl) (algal 2) and (f) FUB Total Suspended Matter (TSM). The land (c-f) and Reef Matrix (c only) are masked in black.

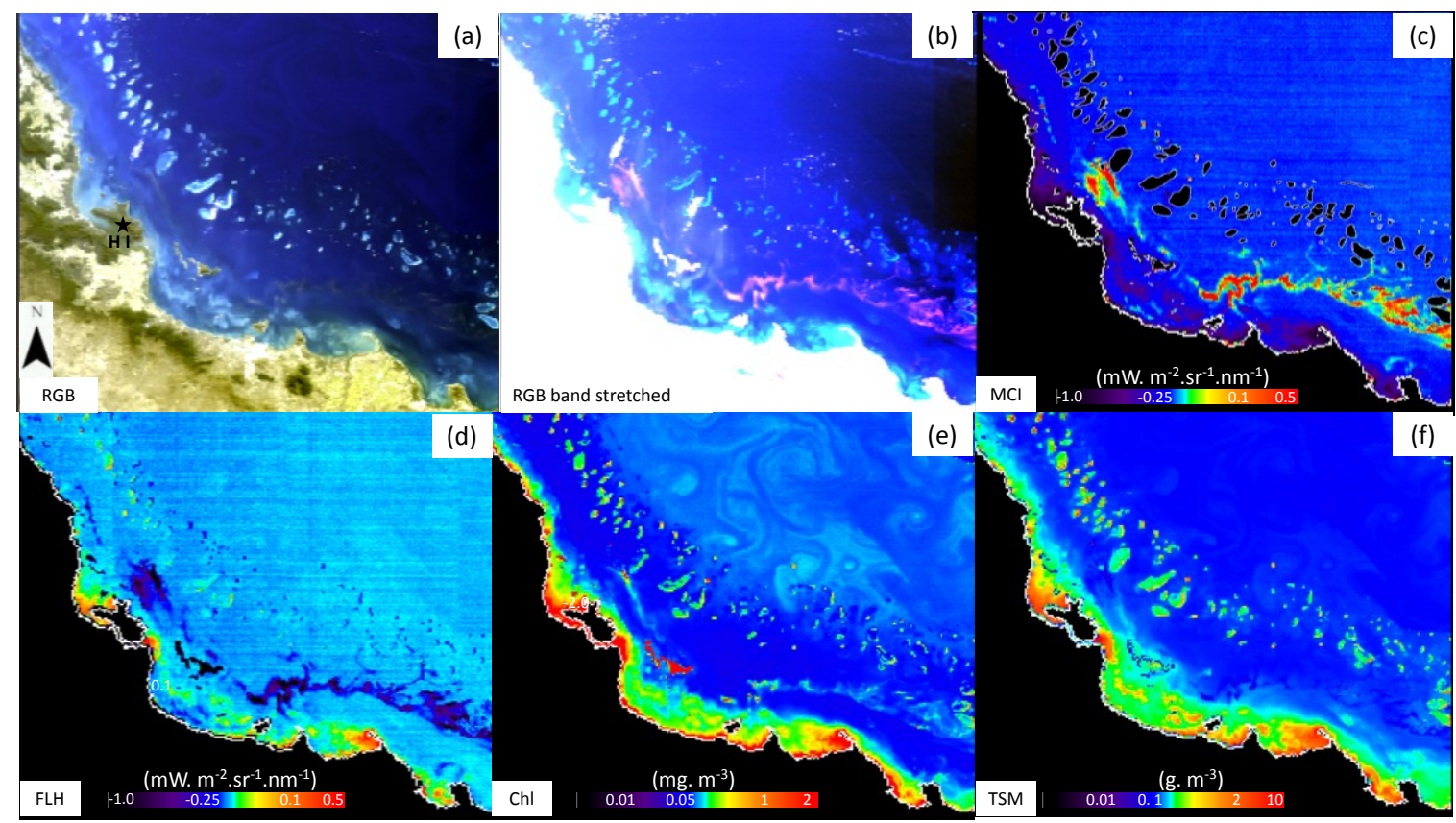




\subsection{Regional Characteristics}

The latitudes of the wet-dry tropics are characterized by a limited amount of runoff most of the year (dry season), followed by a period of extensive flooding (wet season) as a result of heavy monsoonal rainfall [41]. Two-thirds of the yearly rainfall occurs during the wet season months. This substantial seasonal change in rainfall, which is accompanied by an increase in sediment delivery from land-to-coast runoff, has a direct effect on the coastal environment. The length of the wet season may vary depending on the location and the year. Lasting from five to six months per year, the most intense rainfall usually occurs over a period of up to four months. For the GBR, the dry season months extend from May to November, and the wet season spreads from December to April. For the VDG, however, the dry season months are from May to September, and the wet season from November to March. The months of April and October are considered transitional months [42].

The GBR is the world's biggest single structure made by living organisms that is visible from space. It is also the only large-tide dominated reef in the world. In the GBRW, tides are of moderate amplitude $(\sim 4 \mathrm{~m})$ and their associated flows have little contribution to the water transport in this GBR region [43]. With a shallow bathymetry $(30-50 \mathrm{~m})$ and the reef matrix being located $<25 \mathrm{~km}$ from shore, the water composition is largely influenced by the land use in the nearby catchments [44]. Soil erosion from extensive land use has led to increased delivery of suspended sediment and organic matter into the GBR lagoonal waters [3]. The majority (>70\%) of the suspended sediment, organic matter and nutrients exported from freshwater river-runoff into the GBR lagoon originates from the southern GBR (dry tropics), primarily from the Fitzroy and Burdekin rivers, and only $2 \%$ comes from wet tropical catchments $[3,45]$. The coastal waters of Northern Australia have amongst the largest tidal range for a coastline facing an open ocean. The VDG consists of an expansive, shallow $(<20 \mathrm{~m})$ and well-mixed bay. It is a macro-tidal environment that is both oceanographically [4] and optically complex. The Alligator Rivers (i.e., West, South and East) are directly connected to the VDG (Figure 1b) but their freshwater flows are reported to be only substantial during three to four months per year [46]. TSM can exceed $1000 \mathrm{~g} \cdot \mathrm{m}^{-3}$ in the rivers [46], decreasing to $500 \mathrm{~g} \cdot \mathrm{m}^{-3}$ at the river mouths and $50 \mathrm{~g} \cdot \mathrm{m}^{-3}$ in the center of VDG (David K. Williams, Australian Institute of Marine Science, pers.com.).

The VDG and GBRW have similar phytoplankton composition [14], with a predominance of nano- and picophytoplankton [47]. Phytoplankton growth in the oligotrophic waters $\left(0.1<\mathrm{Chl}<1 \mathrm{mg} \cdot \mathrm{m}^{-3}\right)$ of the GBR is primarily limited by nutrient availability $[48,49]$ and therefore phytoplankton blooms usually occur following river discharges or tropical storm events [11]. The near shore lagoonal waters of the GBR typically have a Chl concentration of $\sim 0.2-0.4 \mathrm{mg} \cdot \mathrm{m}^{-3}[44,50]$. During the wet season, GBRW has been shown to exhibit a cross- shelf gradient in phytoplankton, with diatoms found in the mouth and estuarine waters of the Mossman-Daintree rivers and low-to-moderate $\left(0.2-0.6 \mathrm{mg} \cdot \mathrm{m}^{-3}\right)$ biomass of pico-phytoplankton found in the deep lagoon [51,52] (Figure 1a; Figure 2). Phytoplankton blooms with surface signatures commonly occur in Australian tropical waters. This is particularly the case for the naturally occurring cyanobacterium Trichodesmium $s p$. that can be found along the whole east coast of Australia, and more prominently in Queensland (Figure 2), but also in the Northern Territory and north-western Australian coast [53-55]. 


\subsection{Statistics}

Coastal water concentrations of Chl, TSM and other constituents are known for their non-uniform, cross-shelf distributions [56]. To explore qualitatively the change in phytoplankton dynamics occurring in the two study regions, it was necessary to first partition each region into biogeochemical clusters characterized with similar Chl magnitudes over a multi-annual time scale [57]. A K-means clustering was computed under ENVI ${ }^{\circledR}$ from 12 multi-annual, monthly Chl median maps of the two study sites. A maximum of 5 classes and 10 iterations was allowed, with a change threshold of $5 \%$. A post-processing classification of the clustering results was performed using a Majority Analysis to reallocate isolated or spurious pixels to the class belonging to the majority of the pixels comprised within a $3 \times 3$ kernel. For this study, only one cluster was selected for each region. The reef matrix was masked out to exclude reef features from the analysis of the GBRW (Figure 2c). A mask was also designed for the VDG to only select the portion of the selected cluster that is between $130^{\circ}-132.75^{\circ} \mathrm{S}$, extending up to the Cobourg Peninsula (Figure 1b).

To display and help interpret the changes occurring over time and/or space in the GBRW and VDG waters, tile-plots (colored month-by-year matrices of anomalies) and Hovmöller diagrams (latitude-/longitude-time plots) were subsequently computed for the two selected clusters. Tile-plots provide information in regards to changes in trends and magnitude over time, whereas Hovmöller diagrams give a synoptic view of the spatio-temporal variability of each MERIS product. The Jassby and Cloern water quality package for $\mathrm{R}[58,59]$ was used for the computation of boxplots and tile-plots analysis. Tile-plots were used as a statistical tool to detect temporal changes in monthly time-series of the selected MERIS products. Monthly median values were computed for each of the clusters and products. Four bins of log-anomalies (the anomalies are dimensionless and are calculated with respect to the overall mean month) with corresponding colors allow for a visual representation of the temporal variability of a specific MERIS product over the entire mission, both in terms of magnitude and trend. For the Hovmöller diagrams, a monthly median value across each latitude bin (e.g., GBRW), or longitude bin (e.g., VDG) was computed for each cluster. The proportion of non-masked pixels was taken into account in this computation. Only four MERIS images were available for the month of April 2002, therefore this particular month was suppressed from the time-series analysis displayed in the tile-plots, but kept for the Hovmöller diagrams. Trends were assessed using the seasonal Kendall test [60]. The Kendall's tau $(\tau)$ statistics were computed as a non-parametric measure of goodness-of-fit and the statistical significance of the trend was assessed by the p-values. For this study, a $p$-value $<0.05$ indicates statistical significance.

\section{Results}

\subsection{Data Availability and Chl Variability in the Study Regions}

Two processing levels of satellite data were used. As a result the number of satellite observations does vary between the MERIS products because different quality flags were applied. Figure 3 shows the satellite data observations available over the entire MERIS mission for the two regions, based on monthly Chl composites. The pixel availability in the time series was $\sim 80 \%-90 \%$ for the two regions. 
A comparison of weather statistics over a 70 -year period reveals that both regions have an identical mean annual number of cloudy days $(\mathrm{N}=134$ /year; BOM).

Figure 3. Satellite data observations for (a) the Great Barrier Reef Wet tropics (GBRW) and (b) the Van Diemen Gulf (VDG) over the MERIS mission (April 2002-April 2012). The number of available pixels was computed from monthly composites $(\mathrm{N}=133)$.

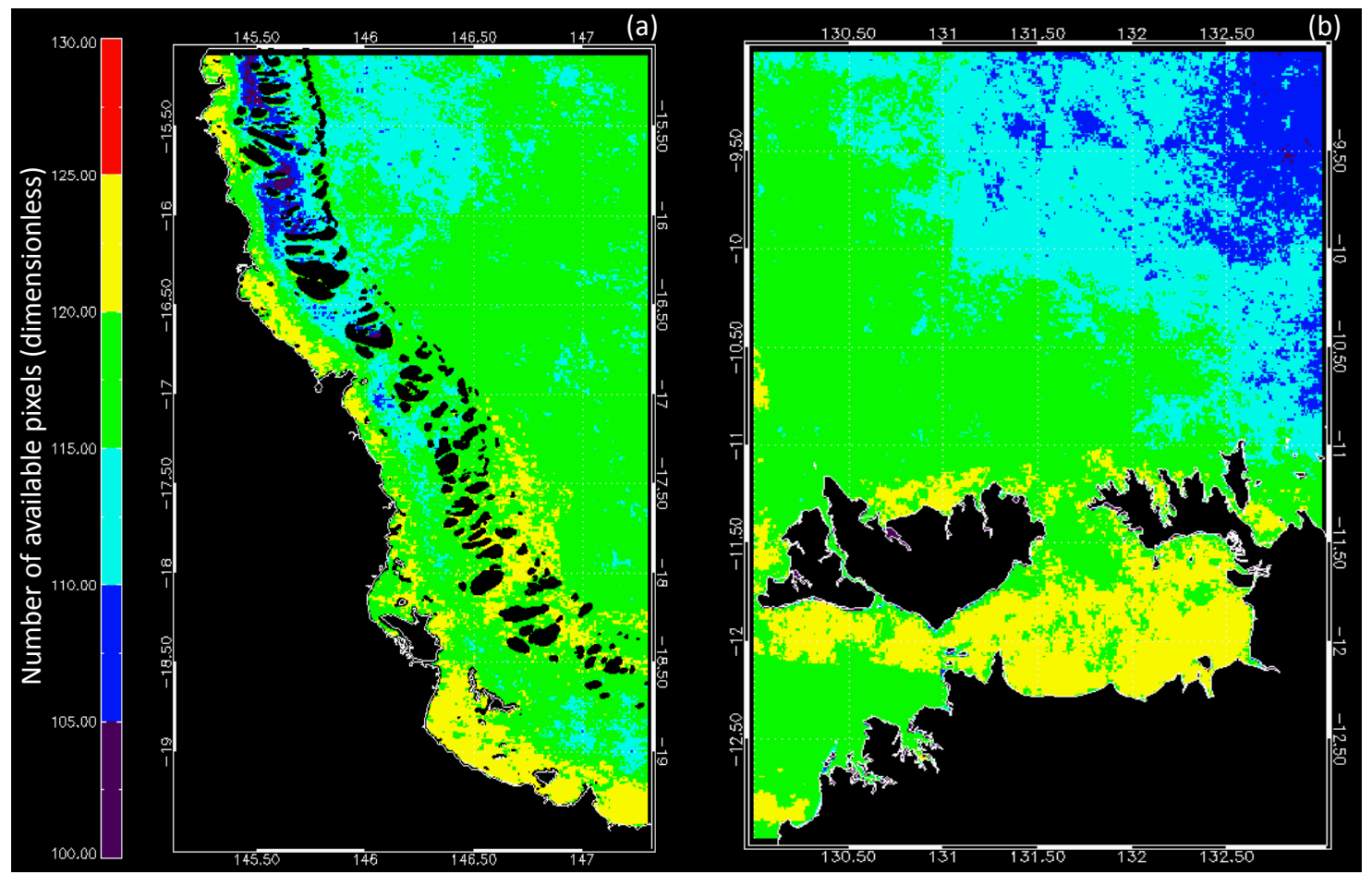

Figure 4. Variability in Chl for (a) the GBRW and (b) the VDG. The coefficient of variation $(\mathrm{CV})$ was computed from monthly composites.

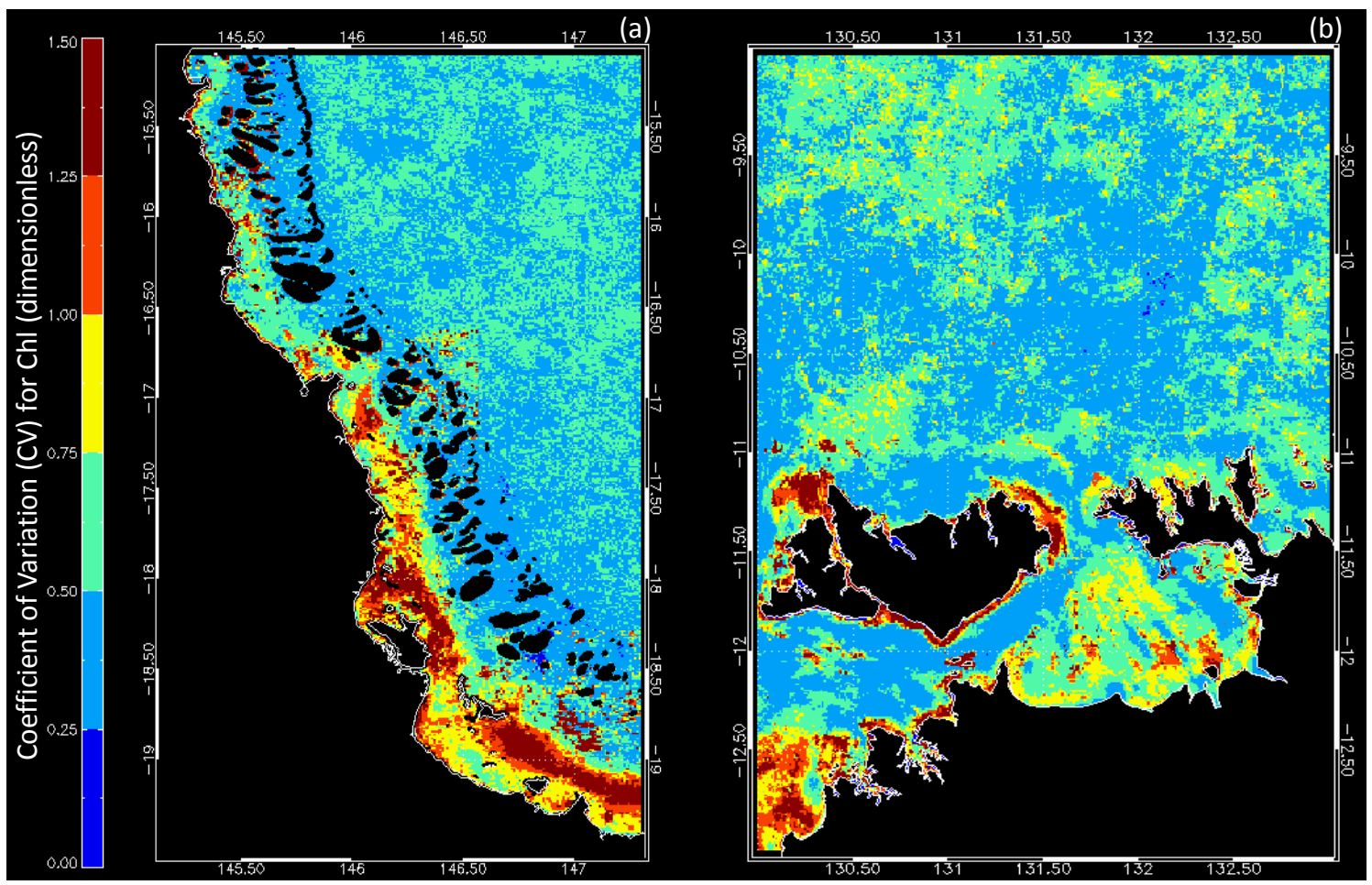


The coefficient of variation (CV) was used to assess the relative spatial distribution of Chl during the entire MERIS mission for the two regions (Figure 4). Overall, a higher variability $(\mathrm{CV}>1.0)$ in $\mathrm{Chl}$ is observed in the GBRW but it is mainly constrained to the coastal band south of $17^{\circ} \mathrm{S}$. A $\mathrm{CV}<0.8$ delineates the transition from the coastal to the oligotrophic waters near the reef matrix, and is also observed closer to shore between $15-17^{\circ} \mathrm{S}$. The center of the VDG is characterized by $0.5<\mathrm{CV}<1.0$ although much larger variability in $\mathrm{Chl}(\mathrm{CV}>1)$ can be observed south-west of Darwin.

\subsection{Cluster Analysis}

The five classes resulting from the K-means clustering analysis performed for the two regions are shown in Figure 5. The clusters selected for this study are the midshelf waters of the GBRW (Figure 5a) and the central VDG (Figure 5b). The other clusters have not been considered but their delineation is shown. The choice of the two selected clusters is based on their size, their location and the variability in Chl (Figure 4). For the GBRW the clustering analysis helped separate inshore waters from the oligotrophic lagoonal waters. The selected cluster for the GBRW is representative of the midshelf waters, a transition zone between the coastal waters and the oligotrophic lagoon. It is homogeneous both in size and shape over the entire region. This is also where the greatest variation in Chl occurs (Figure 5a). For the VDG, the selected cluster is assumed to be representative of the central Gulf conditions, but it is varying in size across the region. From the south-west of Darwin to the eastern tip of Melville Island $\left(130-131.5^{\circ} \mathrm{E}\right.$; Figure 1) the VDG cluster is thin, therefore a lower number of pixels $(<20 \%)$ is used for the computation of the statistics. For the remainder of the cluster up to the Cobourg Peninsula $\left(131.5-132.75^{\circ} \mathrm{E}\right)$, the largest portion $(\sim 80 \%)$ is located within the Gulf. The difference in the cluster's size and shape south-west of Darwin is related to the intrusion of the Timor Sea and the small size of the nearby Adelaide River catchment $\left(\sim 131^{\circ} \mathrm{E}\right)$. By comparison, the high quantity of material discharged from the Alligator Rivers is trapped in the near shore waters due to sand banks, thus favoring a cluster with a larger size in the center of the Gulf.

\subsection{Time-Series}

Boxplots of Chl and TSM concentrations for the VDG and GBRW clusters are shown in Figure 6. Overall, the VDG exhibits much higher Chl and TSM concentrations in comparison to the GBRW. The effect of seasonality can be seen for both products. The Chl peak occurs during March to April in the GBRW, and from May to June in the VDG. TSM peaks in May to June in the GBRW and shows a general increase between April and July. TSM peaks early during the dry season (June) in the VDG. Tile plots were computed for each product for the GBRW (Figures 7-10) and the VDG (Figures 11-14).

Overall, the seasonal variation in Chl and TSM in the tile-plots reflects that of the boxplots. In the GBRW, the magnitudes in Chl (Figure 7) between January and April have increased since 2007, while TSM shows less variability. Less substantial Chl anomalies also occur outside those months in October 2006, June-July 2010 and September-October 2011. 
Figure 5. K-means Chl clustering results for (a) the GBRW and (b) the VDG. Each cluster class $(\mathrm{N}=5)$ is shown by a different color. The clusters selected for this study are shown in blue.

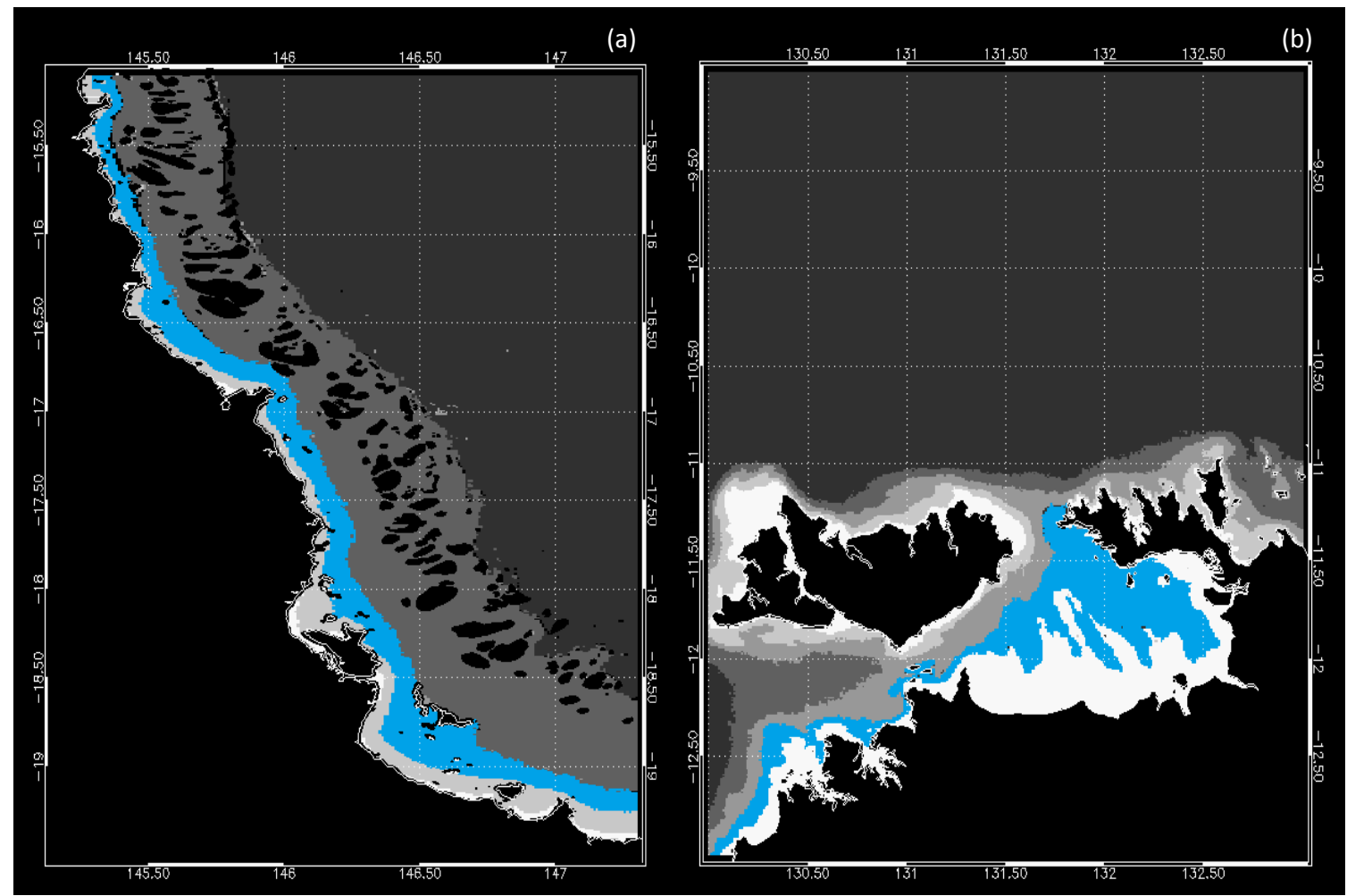

Figure 6. Boxplots of monthly Chl and TSM for the GBRW (a,c) and VDG (b,d) clusters based on the MERIS 10-year dataset. The boundary of the box indicates the 25 th and 75 th percentiles, the line within the box indicates the median, the whiskers above and below the box indicate the 90th and 10th percentiles, and the dots outside the box are outlying values.

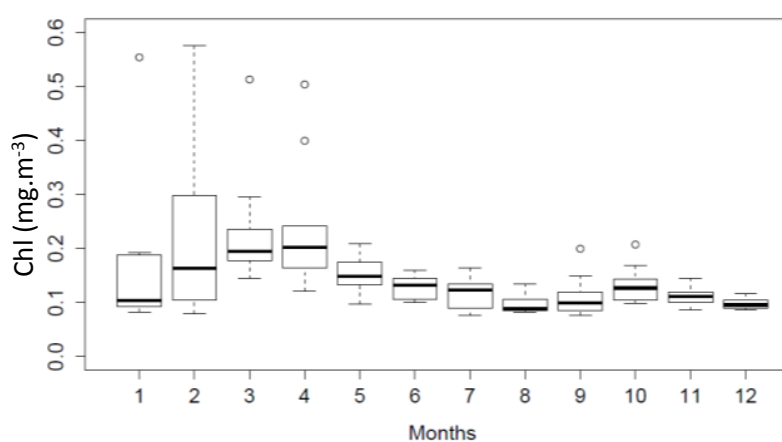

(a)

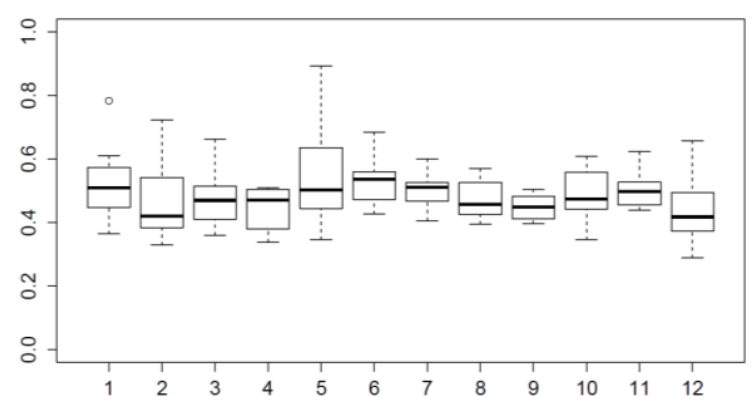

(b)

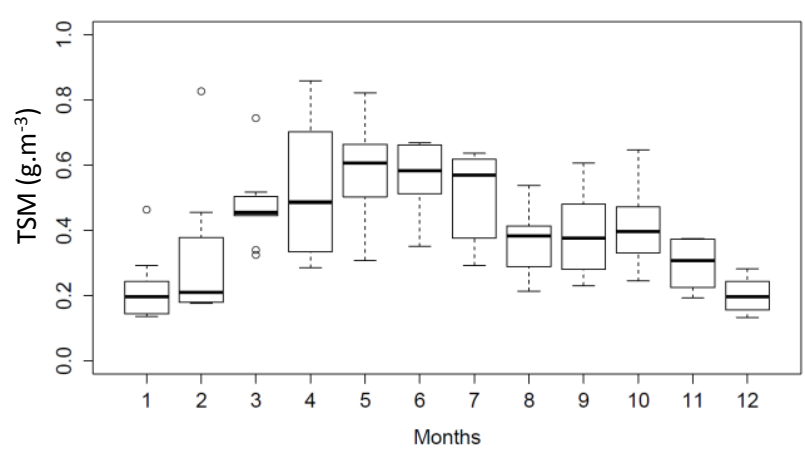

(c)

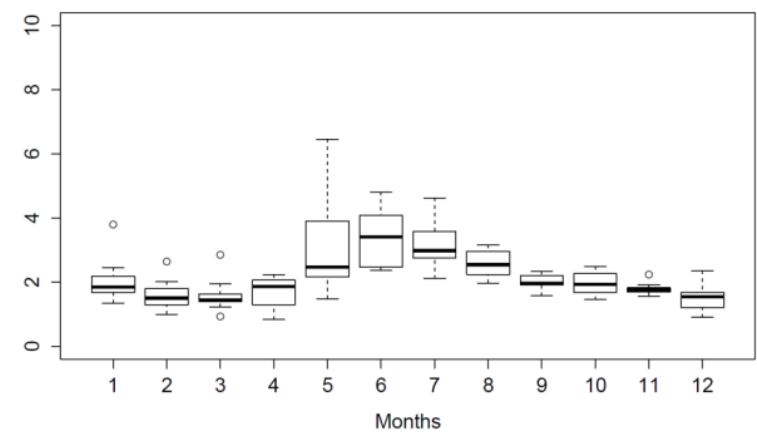

(d) 
Outside the seasonal increase between April-July, TSM anomalies (Figure 9) occurred in February 2007, and September-October 2011 consistent with Chl. The seasonality in FLH (Figure 8) occurs between October-April in the GBRW, contrasting with the VDG maximum being reached between May and August. For the GBRW, MCI increases from May to September and peaks between July-August. However there is an overall decrease in MCI magnitude observed from 2006 onwards (Figure 10).

From 2007, a distinct change in magnitude in Chl (Figure 11) and TSM (Figure 13) can be observed for the VDG. Both Chl (Sen slope $=-2.85 \% /$ decade, $\tau=-0.32, p<0.01$ ) and TSM (Sen slope $=-3.57 \%$ /decade, $\tau=-0.24, p<0.01$ ) were found to have a weak decreasing trend in the VDG, while trend statistics were found not to be significant for the same products in the GBRW. FLH (Figure 12) showed a uniform pattern of increasing signal between May and August, while MCI (Figure 14) showed changes around October with an isolated event in August 2008. Seasonal patterns displayed by FLH (Figure 12) are similar overall across the entire mission.

Figure 7. Tile-plot of Chl for the GBRW cluster (log-anomalies).

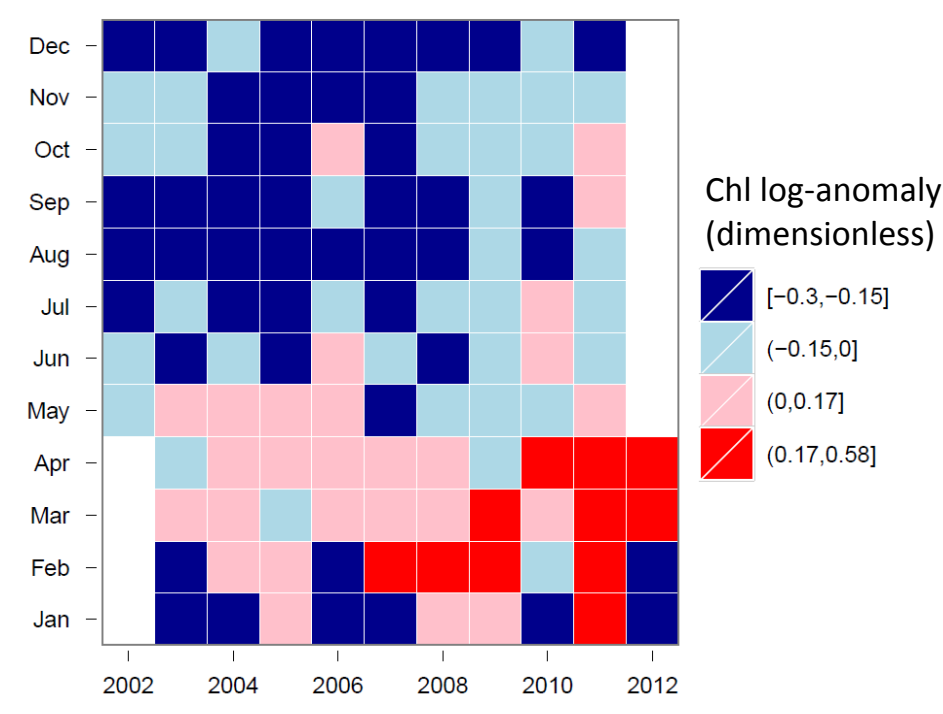

Figure 8. Tile-plot of FLH counts for the GBRW cluster (log-anomalies).

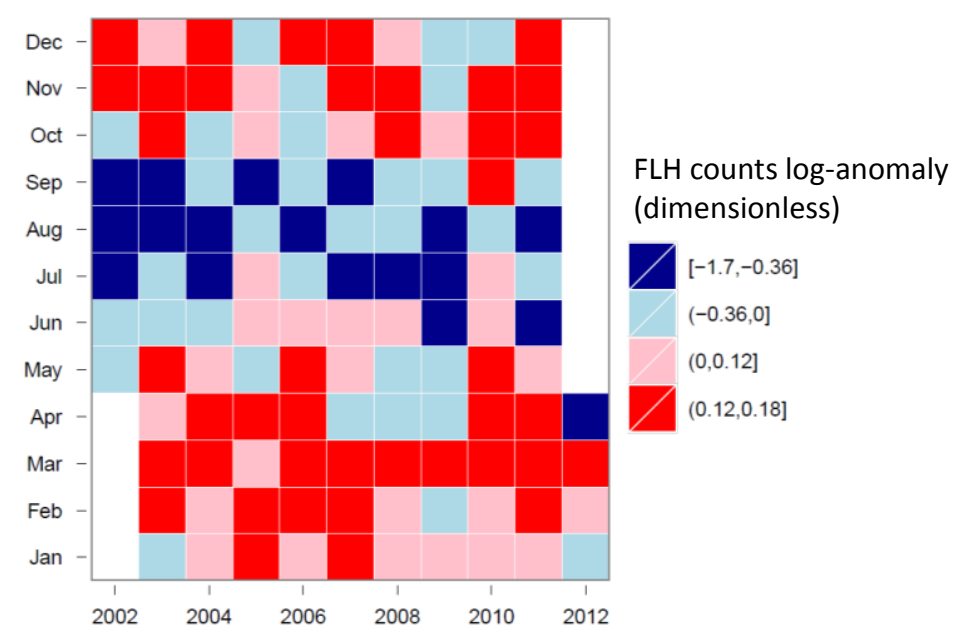


Figure 9. Tile-plot of TSM for the GBRW cluster (log-anomalies).

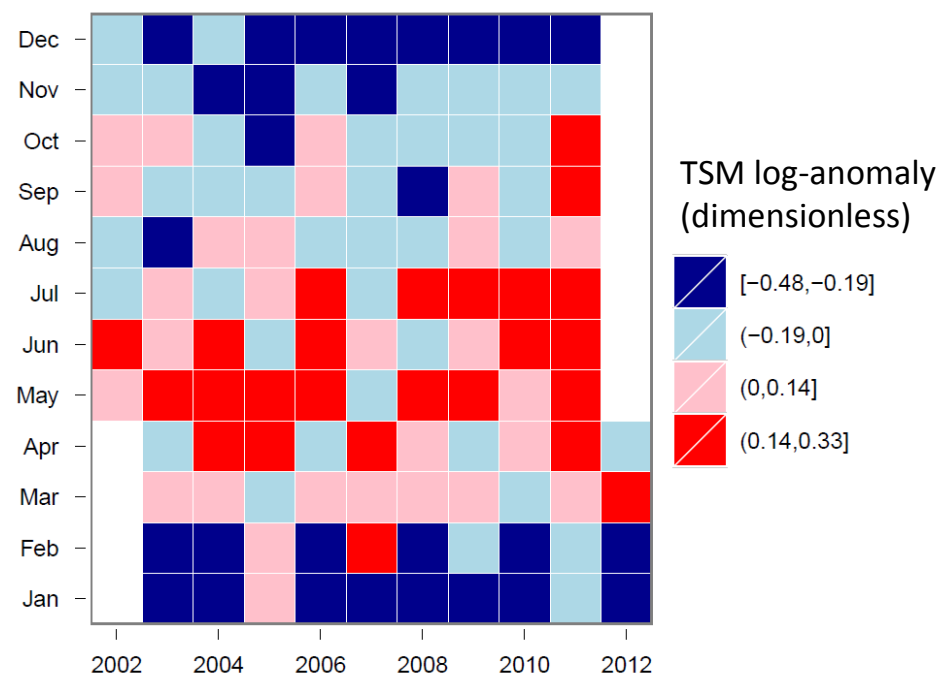

Figure 10. Tile-plot of MCI counts for the GBRW cluster (log-anomalies).

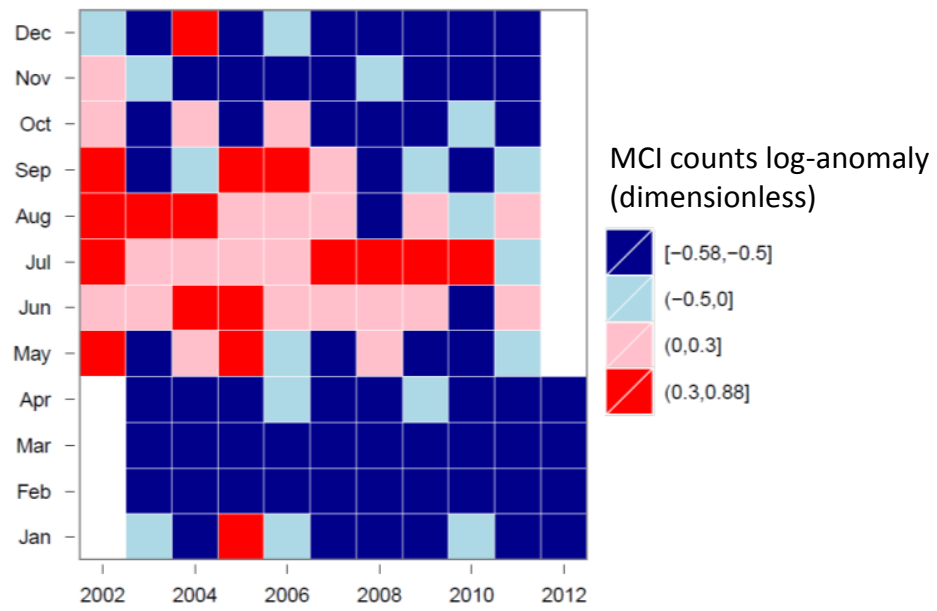

Figure 11. Tile-plot of Chl for the VDG cluster (log-anomalies).

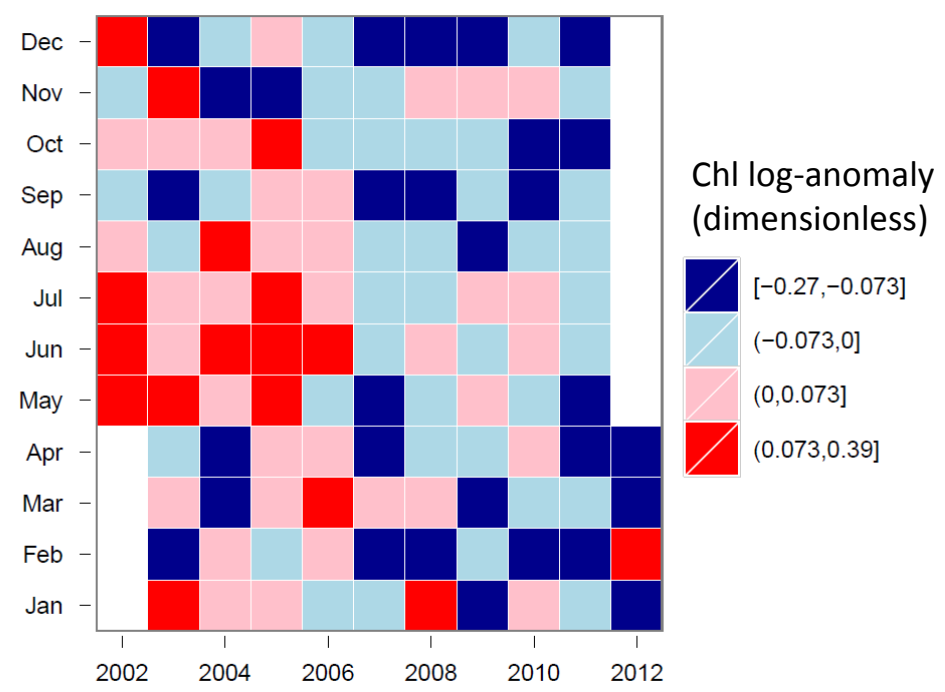


Figure 12. Tile-plot of FLH counts for the VDG cluster (log-anomalies).

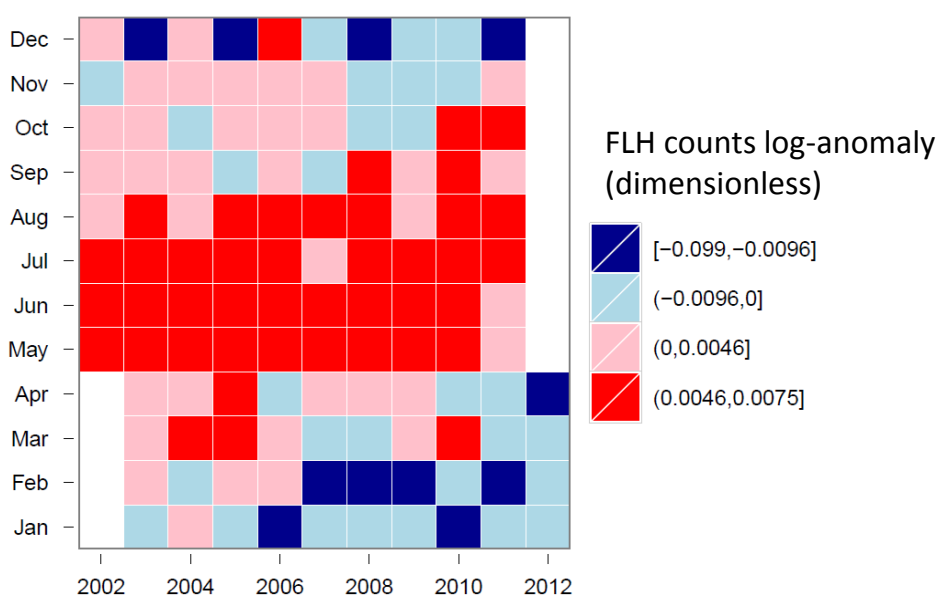

Figure 13. Tile-plot of TSM for the VDG cluster (log-anomalies).

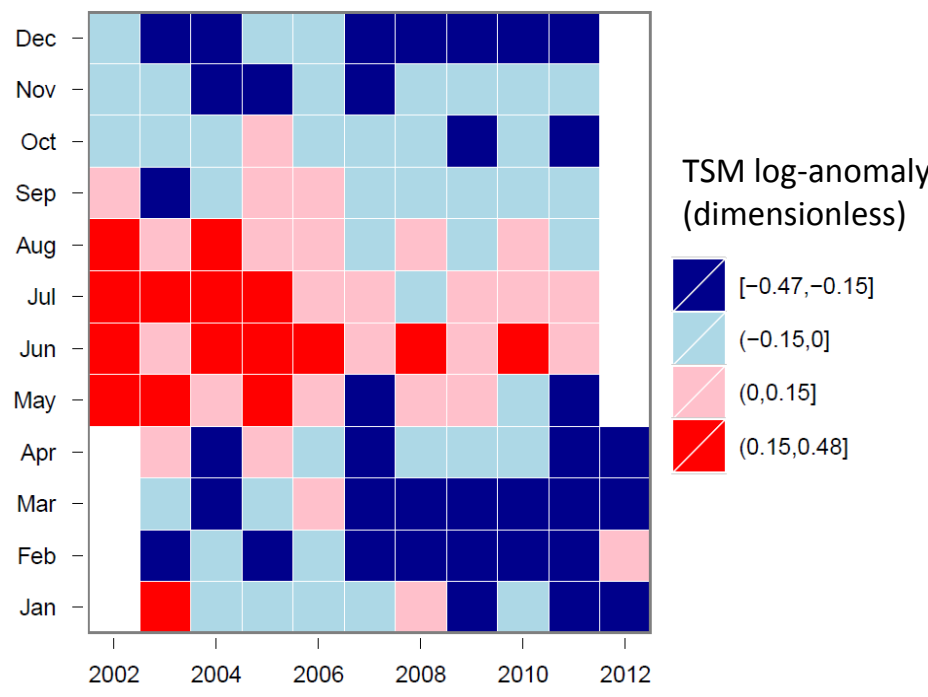

Figure 14. Tile-plot of MCI counts for the VDG cluster (log-anomalies).

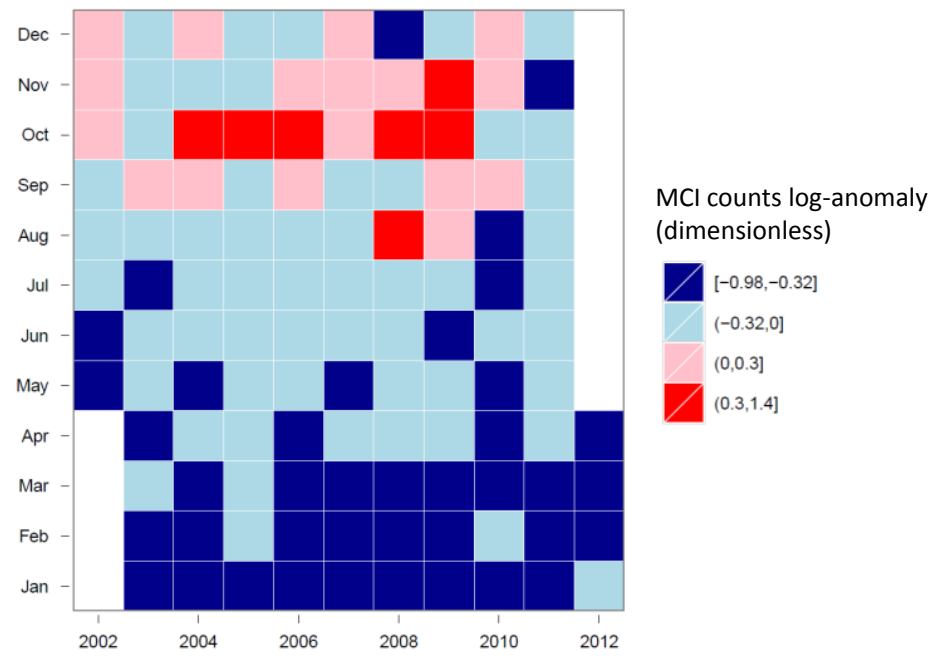




\subsection{Hovmöller Diagrams}

The spatio-temporal history of Chl, FLH, TSM and MCI is presented in Figures 15-18 for the midshelf waters of the GBRW and in Figures 19-22 for the VDG. Overall, a regular seasonal pattern can be seen in all diagrams, though with differences depending on the satellite product.

Figure 15. Latitude-time plot of Chl for the GBRW cluster.

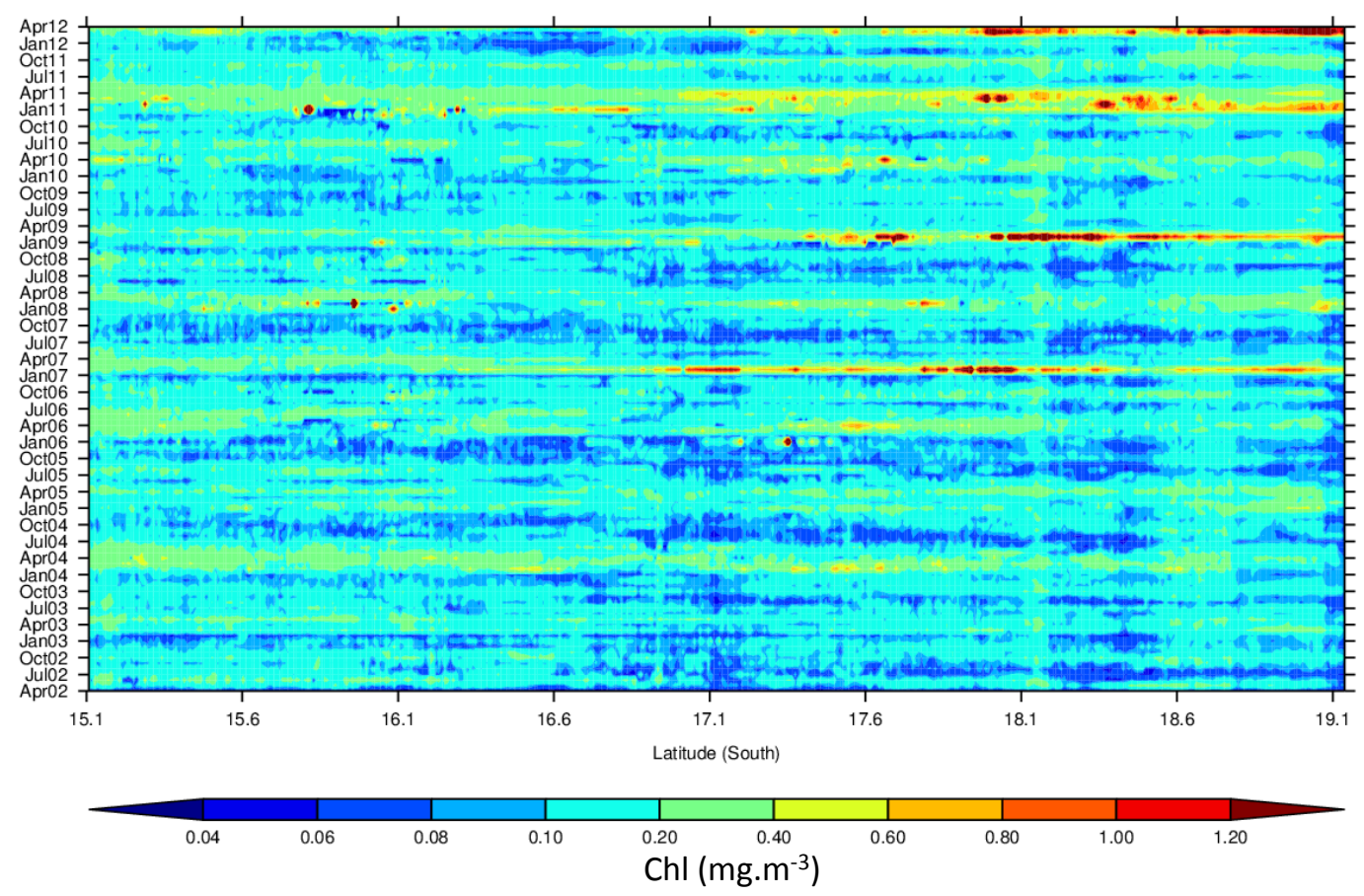

For the GBRW, the history of Chl (Figure 15) shows a seasonal increase in March-April from 0.04 to $>0.40 \mathrm{mg} \cdot \mathrm{m}^{-3}$. The increased frequency of land-to-coast water runoff after the start of the wet season in December in the GBRW generates a progressive build-up of nutrients in the near-shore waters between January-March. Spatially, the Chl seasonality displayed in the Hovmöller reflects that of the tile-plots. An increase in Chl over the years can be observed, mostly between $15-17.5^{\circ} \mathrm{S}$. This increase in $\mathrm{Chl}$ seasonality tends to extend towards $19^{\circ} \mathrm{S}$ after 2007. The FLH (Figure 16) displays regular seasonal patterns that match those of $\mathrm{Chl}$, albeit with greater increases outside of the seasonal peaks. A seasonal increase in FLH $\left(\sim 0.1-1 \mathrm{~mW} \cdot \mathrm{m}^{-2} \cdot \mathrm{sr}^{-1} \cdot \mathrm{nm}^{-1}\right)$ occurs regularly between October and April (wet season), and peaks between January and March (as per Chl). Spatially, FLH patterns in the Hovmöller also reflect the distribution of Chl. Temporally, as per Chl, FLH tends to increase over the years. TSM (Figure 17) displays mild changes (up to $\sim 2 \mathrm{~g} \cdot \mathrm{m}^{-3}$ ) for most years between $16.5-18^{\circ} \mathrm{S}$.

High values of TSM were observed at $18.0-19.1^{\circ} \mathrm{S}$ during the 2007, 2009, 2011 and 2012 wet seasons. The MCI (Figure 18) displays a seasonal increase in counts ( $>10)$ between the months of July and October. Most of the surface expressions from phytoplankton blooms occur south of Cairns $\left(17.6^{\circ}-19^{\circ} \mathrm{S}\right)$ (Figure 2; Figure 10; Figure 18), although sporadic surface bloom events may also take place further north.

Surface phytoplankton blooms may occur between April and July, but do so rarely (counts $<5$ ). The surface bloom on 30 July 2008, shown in Figure 2, can also be observed in Figure 18 at the latitudes $18.6-19.1^{\circ} \mathrm{S}$. 
In the VDG, higher Chl (Figure 19) is observed primarily south-west of Darwin $\left(130.25^{\circ}\right)$ and near the Adelaide $\left(131^{\circ} \mathrm{E}\right)$ and Alligator $\left(131.5-132.5^{\circ} \mathrm{E}\right)$ rivers. The Chl signal increases in intensity $\left(\mathrm{Chl}>1.25 \mathrm{mg} \cdot \mathrm{m}^{-3}\right)$ between October and November for the waters close to Darwin, around January for waters near the Adelaide River, and between April and July for the Alligator rivers. For the remainder of the year, Chl shows occasional increases $\left(\mathrm{Chl} 1.0 \mathrm{mg} \cdot \mathrm{m}^{-3}\right.$ ) around January during episodic events.

Figure 16. Latitude-time plot of FLH for the GBRW cluster.
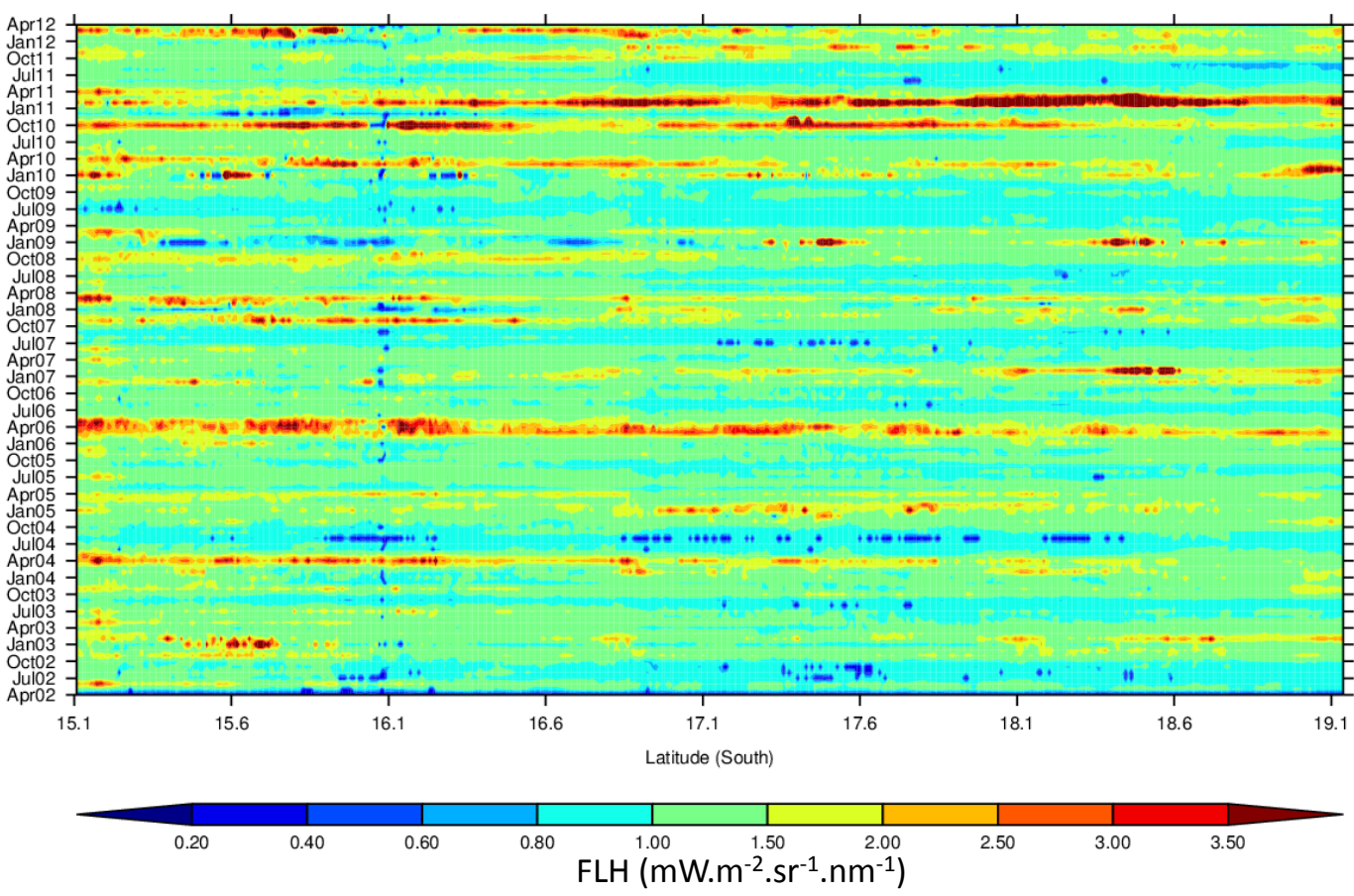

Figure 17. Latitude-time plot of TSM for the GBRW cluster.

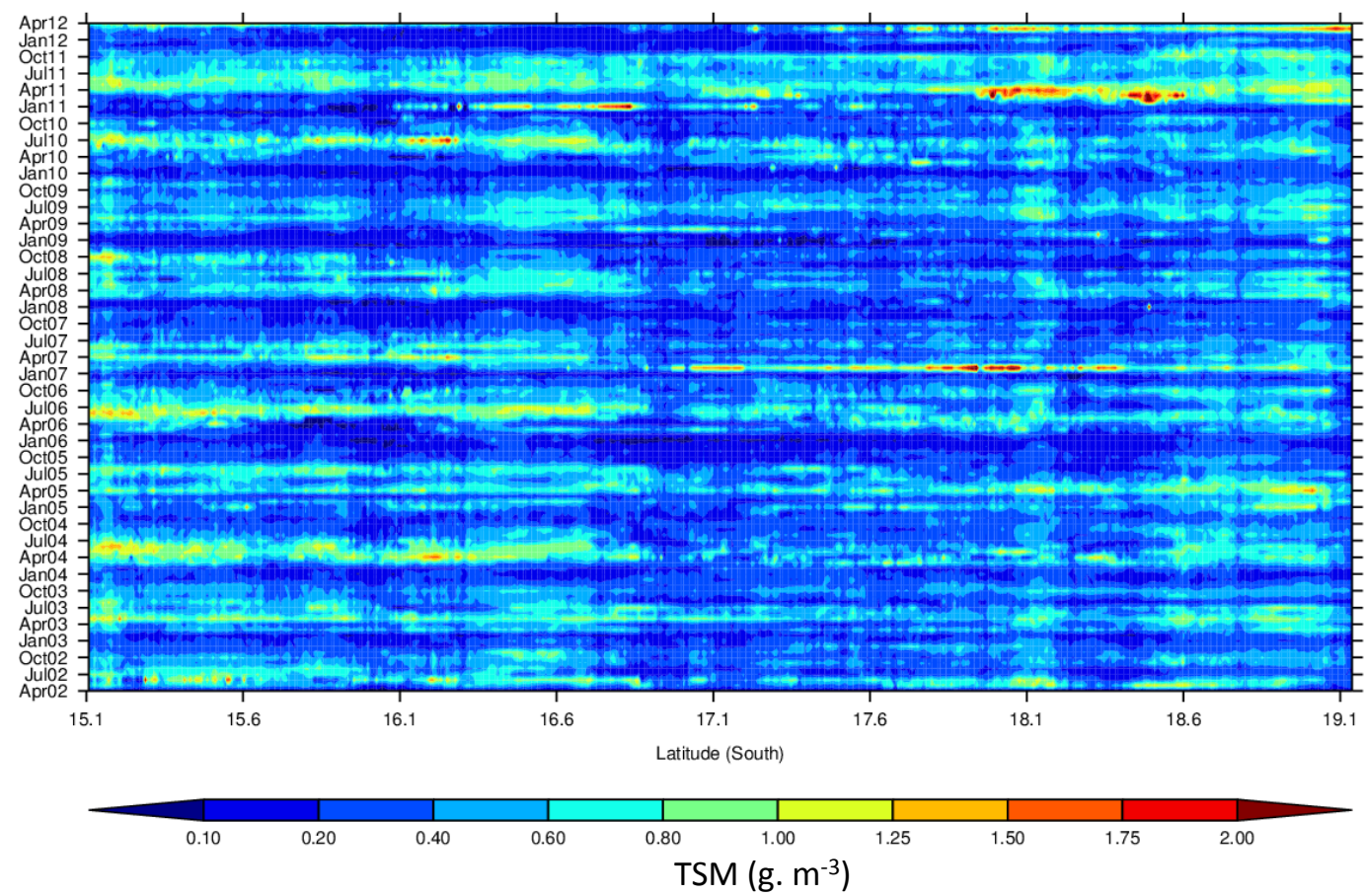


Figure 18. Latitude-time plot of MCI counts for the GBRW cluster. The surface bloom event of 30 July 2008 (Figure 2) can be seen (18.6-19.1 $\left.{ }^{\circ} \mathrm{S}\right)$.

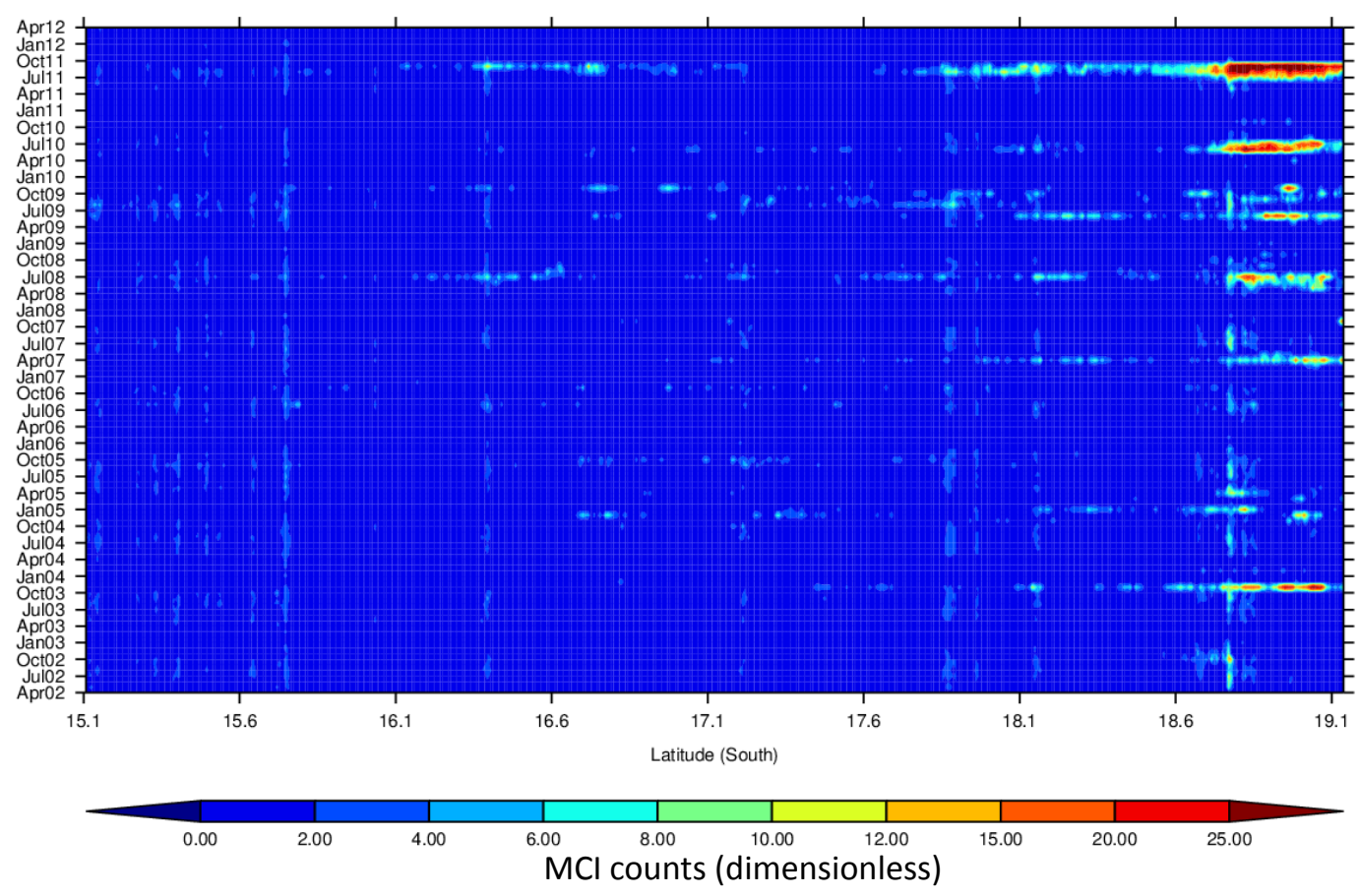

Figure 19. Longitude-time plot of Chl for the VDG cluster.

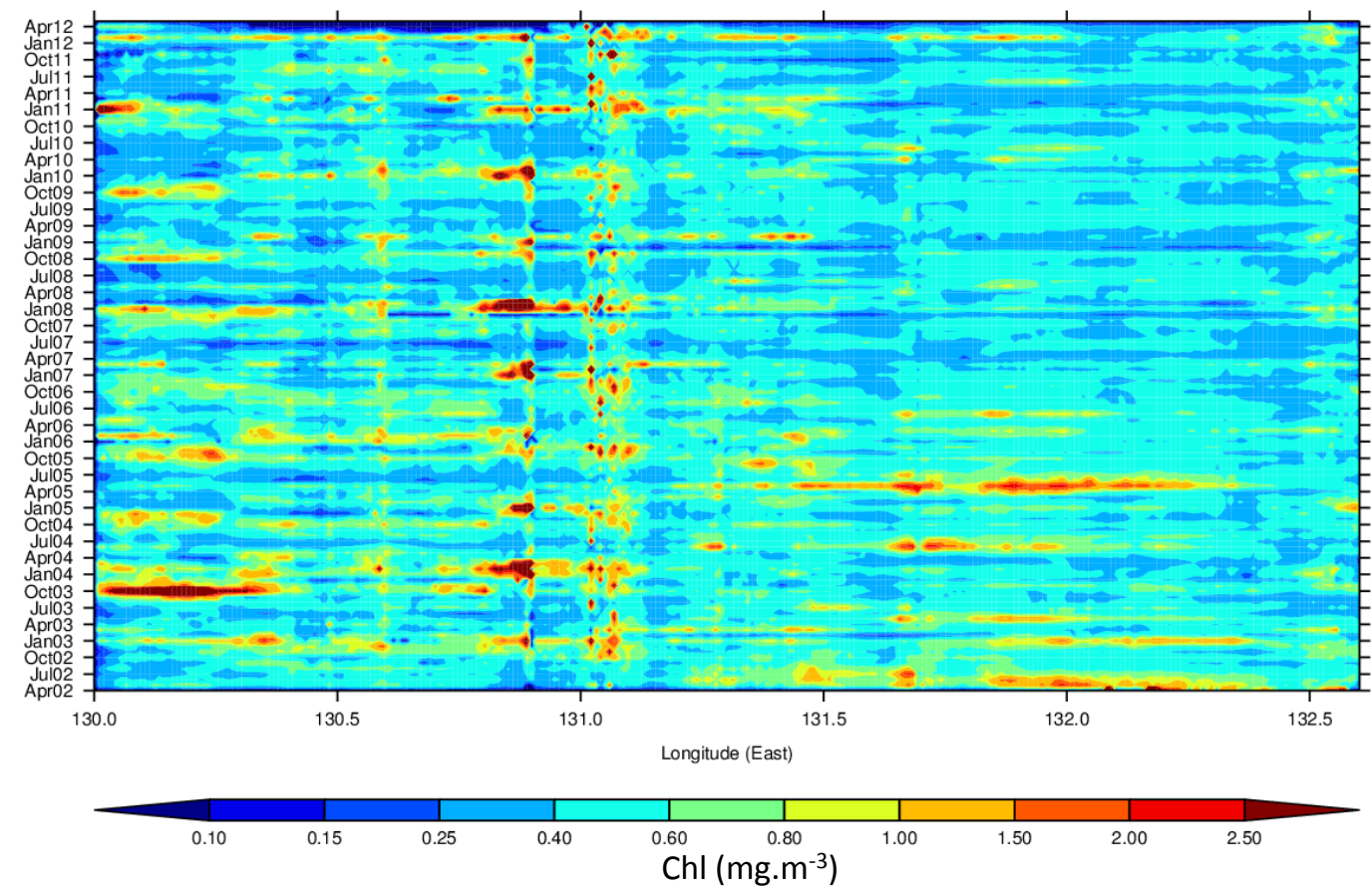

FLH (Figure 20) displays more complex patterns than those of Chl for the VDG. An increase in FLH $\left(>1 \mathrm{~mW} \cdot \mathrm{m}^{-2} \cdot \mathrm{sr}^{-1} \cdot \mathrm{nm}^{-1}\right)$ is observed between January and April for most of the VDG, but a much stronger seasonal signal occurs between April and July (as per the corresponding tile-plots) mainly near the Alligator Rivers $\left(131.5-132.5^{\circ} \mathrm{E}\right)$. Episodic increases in FLH also occur mostly between September and October. Increase in TSM (Figure 21) is generally constrained to the dry season (May-September). 
Figure 20. Longitude-time plot of FLH for the VDG cluster.

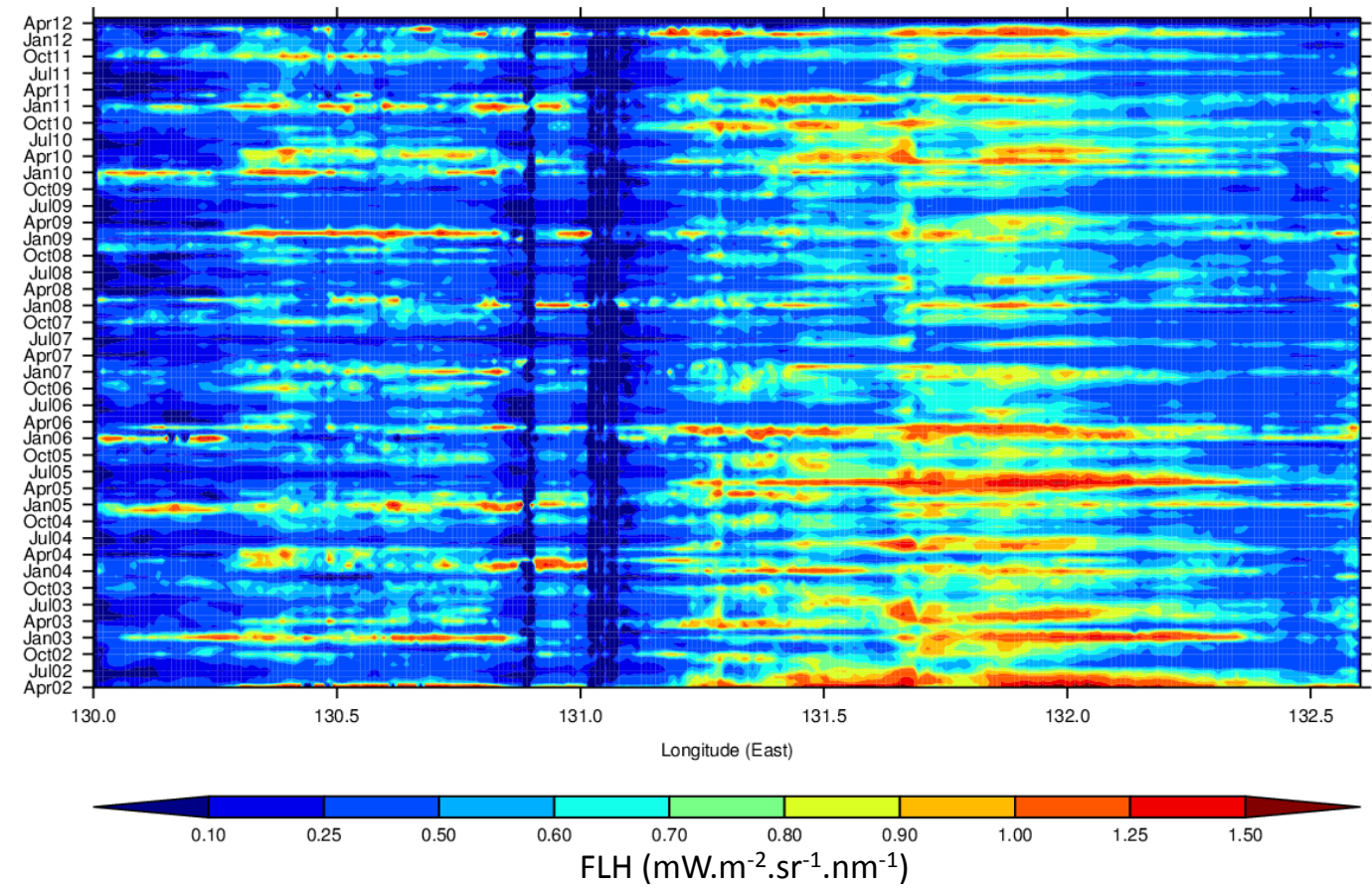

Figure 21. Longitude-time plot of TSM for the VDG cluster.

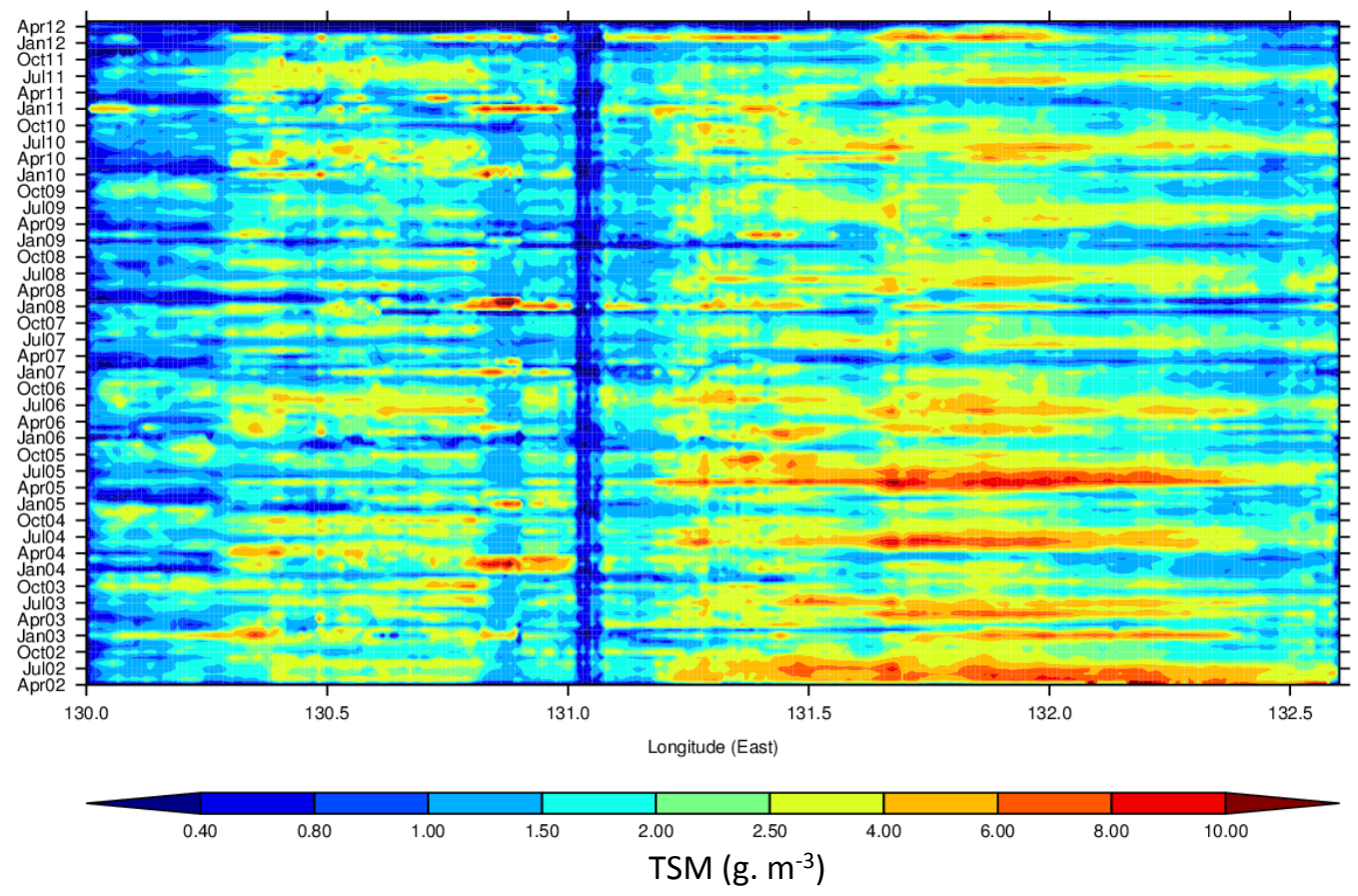

As per the tile-plot, a decrease in the intensity of the seasonal TSM signal can also be observed from 2006 onwards, which is visible in the Hovmöller (Figure 21) for the Gulf section only. The western part of the VDG displays less variability in Chl and TSM, though the MCI (Figure 14; Figure 22) does show a seasonal increase around October and its magnitude tends to change between years. The MCI signal was the most prominent in August 2008 (Figure 14) in the center of the VDG, and appears to occur irregularly south-west of Darwin (Figure 22). The narrow section between the Timor Sea and 
the Van Diemen Gulf shows a minimum in TSM and regular MCI counts for the most western part of the Gulf across the entire time-series.

Figure 22. Longitude-time plot of MCI counts for the VDG cluster.

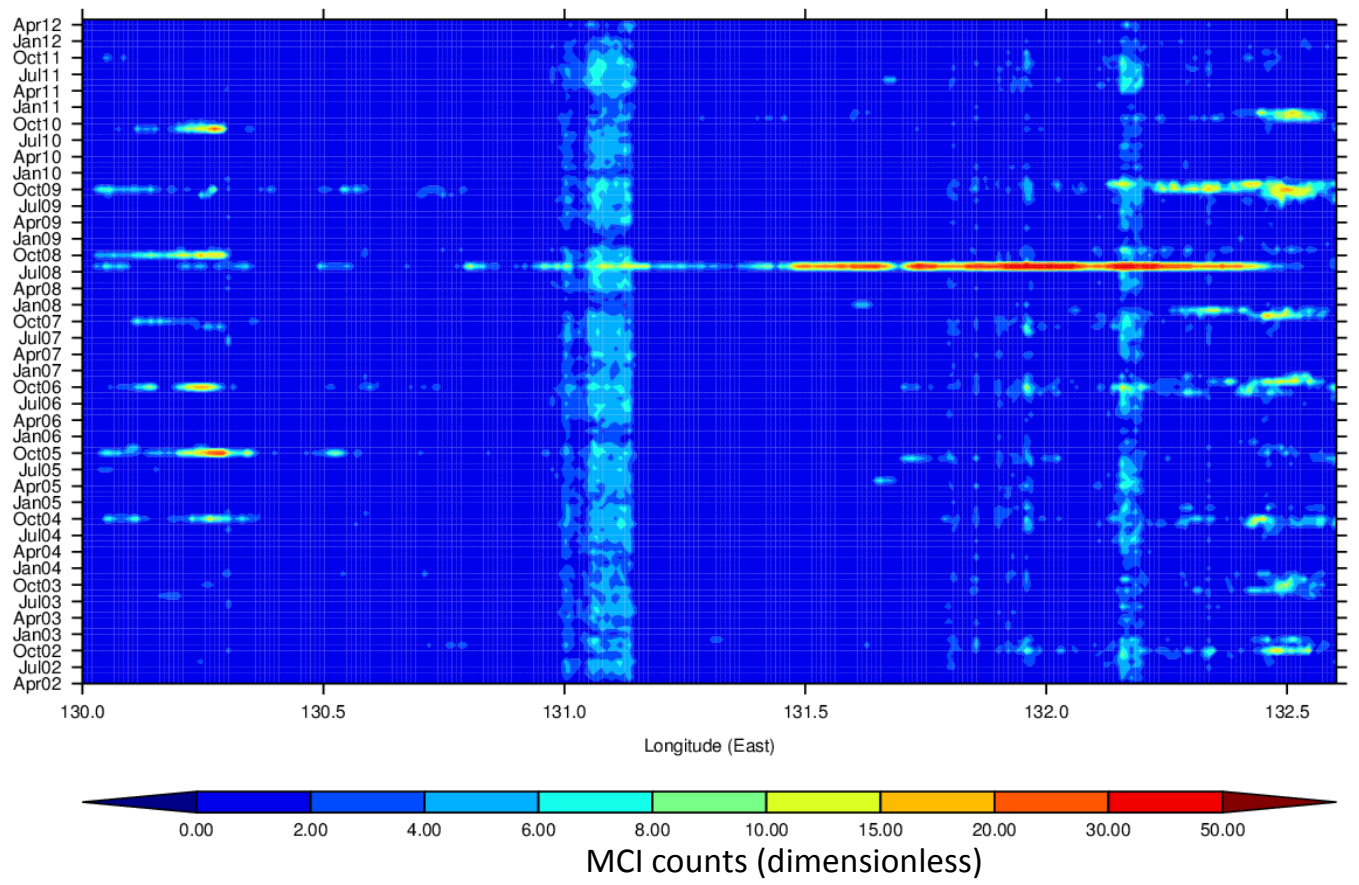

\section{Discussion}

\subsection{Spatio-Temporal Phytoplankton Dynamics in the GBR Wet Tropics}

For the GBRW, the reef matrix is very close to shore $(<25 \mathrm{~km})$, which implies that the selected cluster for this study (Figure 5) may be impacted by river runoff much faster that in the southern GBR, where the reef matrix is further off-shore (up to $250 \mathrm{~km}$ ) [41,61]. The midshelf waters therefore benefit from more frequent freshwater discharges from the adjacent rivers. Terrestrial nutrient inputs generate a higher productivity and a higher frequency of bloom occurrences when contrasted with the oligotrophic lagoon. The seasonal cycle of $\mathrm{Chl}$ in this cluster is characterized by a maximum between January and April (Figure 7; Figure 15), a decrease between May and July, and a low from June to December. This seasonal decrease in Chl is associated with the peak in TSM concentrations (Figure 9) around May $[62,63]$. The influence of inflows from the Coral Sea into the reef matrix also needs to be considered as a factor favoring the seasonal maximum early in the year, in particular for the northern GBRW (15.0-16.5 $\mathrm{S}$; Figure 5) where the reef matrix is even closer to shore [64]. Estimates of flushing times in the central and northern GBR have demonstrated that the location and magnitude of water fluxes was influenced by the spatial variability of the complex bathymetry, as well as the density of the reef matrix. Across-shelf oceanic inflow from the Coral Sea can reach $6 \times 10^{5} \mathrm{~m}^{3} \cdot \mathrm{s}^{-1}[64,65]$, bringing in nutrients that distribute rapidly across the shelf. The FLH (Figure 16), with patterns similar to that of Chl (Figure 15), provides further indication of the presence of increased phytoplankton biomass early in the wet season (October-December) and also early in the dry (May-June) (Figure 8; Figure 16) within TSM-dominated waters [66]. The increase of TSM between 2007 and 2012 (Figure 9; 
Figure 17) coincides with the Burdekin flood [67] and strong La Niňa conditions which triggered above-average rainfall and tropical cyclones [44]. The wet seasons of the years 2007, 2009, 2011-2012 were also associated with higher Chl (Figure 15; Figure 7) as a result of an enhanced nutrient supply from the ecological disturbance caused by tropical cyclones Hamish (March 2009) and Yasi (February 2011) and other increased river discharges. Tropical cyclones occurring on the east coast of Australia are often confined to the northern GBR, but the north-to-south track of cyclone Hamish was unusual because it followed the whole reef matrix, impacting other regions further south. Large parts of north and central Queensland received above average rainfall, with the heaviest on record (BOM) being centered near the Johnstone and Tully $(>800 \mathrm{~mm})$ and Herbert $(>200 \mathrm{~mm})$ rivers $\left(17-19^{\circ} \mathrm{S}\right)$ (Figure 1a). A stronger signal in TSM can be seen at those latitudes for those years (Figure 17). Recent studies have reported disturbances created by tropical cyclones on marine ecosystems which led to an increase in biogeochemical concentrations $[68,69]$ and noticeable changes in composition and biomass of phytoplankton communities [70,71].

From the monthly MCI climatologies (Figure 10; Figure 18), surface blooms occur during the dry season between May and September in the GBRW. The annual cycle of surface phytoplankton blooms, as derived from MCI, characterizes blooms that are most likely not composed of Chl, such as those of Trichodesmium sp. The combined use of MCI, Chl, and FLH allows for the discrimination of two different bloom types. It is also likely that pixels contaminated by surface algal bloom slicks lead to an algorithm failure of the Level $2 \mathrm{Chl}$ processing. The near-infrared spectral signatures of these pixels, showing a red-edge, were not included in the neural network training for Chl. Phytoplankton blooms with surface expressions in the GBRW usually peak between July and August (Figure 10) but only at specific latitudes (Figure 18) within the region. The timing of those surface blooms is anti-correlated with FLH (Figure 2; Figure 8; Figure 10). The lack of fluorescence during cyanobacteria blooms could be explained by the absence of fluorescence yield. Photosynthesis is carried out by two photosystems that are very similar among plants, PS1 and PS2, but the principal light-harvesting complex in cyanobacteria is predominantly in the non-fluorescing PS1, with PS2 accounting for relatively little of the Chl molecules [72].

\subsection{Spatio-Temporal Phytoplankton Dynamics in the Van Diemen Gulf}

In the Australian-Indonesian region, the Arafura Sea (Figure 1) is characterized by a strong transition in sea-surface temperature and ocean surface winds between seasons [42,73]. Cooler sea-surface temperatures $\left(25 \sim 26^{\circ} \mathrm{C}\right)$ characterize the dry season months (May-September) and are associated with south-easterly winds that push the VDG waters towards the Arafura Sea. In addition, the shallow depths and oceanographic intricacies [4] of the region add to the complexity of the VDG when compared to GBRW. As a result, the various satellite products used in the VDG show mostly semi-annual spatial patterns (Figure 11; Figure 19). Chl increases between May and July (dry season) for the center of the VDG $\left(131.25-132.5^{\circ} \mathrm{E}\right)$ (Figure 6; Figure 11; Figure 19), while the western portion of the region $\left(130-131.5^{\circ} \mathrm{E}\right)$ usually shows a seasonal cycle between October-January (wet season). The seasonal variability in the ocean color products in the center of the VDG, occurring mainly around June, is in accordance with previous studies [42]. Three of the ocean color products (Chl, FLH and TSM) display a pronounced decrease in intensity after 2005. FLH only replicates parts 
of the Chl patterns. A much stronger FLH signal is observed between April and July in the center of the Gulf, but also around January for the entire region, and for all years (Figure 12; Figure 20). While there is comparatively little river discharge during the dry season months, other physical forces, such as winds and tidal energy, are likely to play a major role in the recycling of nutrients in the VDG, thus triggering a phytoplankton response during those months. It is also possible that the TSM signal occurring most of the year in the center of the VDG is related to both sediment discharges during the wet season and sediment resuspension from south-easterly winds during the dry season. Wind-driven resuspension occurs between May and November because winds are usually at their strongest during this period. MCI counts for the VDG are rather low $(\sim 10)$ and sporadically distributed across the region. They predominantly occur around October in the center of the Gulf. This is in accordance with the results found for the GBRW. The distribution and occurrence of Trichodesmium sp. is strongly influenced by several factors, including surface water temperature and water column stability, as well as salinity and iron availability [74,75]. Trichodesmium $s p$. optimum growth rate occurs at a temperature of $25^{\circ} \mathrm{C}$, at salinity of $>30 \mathrm{PSU}$ and mainly during stable water column conditions, that may follow a period of mixing. The dynamic coastal environment of the VDG may not favor the growth of Trichodesmium. Water column mixing, for instance, might hinder its development, thus the small number of occurrences reported in the diagrams analyzed.

\section{Conclusions}

Continental shelves of the world's oceans play important ecological functions as they are the buffer between the land and the open ocean [76]. The ever-increasing anthropogenic pressures on coastal environments have multiple impacts, some of which are yet to be quantified. The monitoring of phytoplankton blooms is considered a direct proxy for coastal ecosystem health, thus there is an important need to monitor them worldwide [77]. The objective of this study was to qualitatively analyze spatio-temporal patterns of phytoplankton blooms in two bio-diverse, understudied tropical coastal regions of Northern Australia. The analysis made use of four MERIS products (TSM, Chl, FLH, MCI) and a 10-year dataset (April 2002-2012). The coastal waters of the GBRW (Cairns) and the VDG were found to be contrasting in their Chl and TSM concentrations. The distinction is mainly due to the differences in regional land use in the river catchments as well as the complex oceanography, which ultimately impact on the dynamics of regional phytoplankton blooms. In the GBRW, phytoplankton blooms increase early in the wet season (between January and April), mostly south of Cairns, as a response to terrestrial runoff. In the VDG Chl maxima are observed during both wet and dry seasons - nearby Darwin from October to January, and in the center of the Gulf from April to July. Those occurrences are driven by seasonal runoff, as well as wind and tidal energy which recycle nutrients during the dry season months. The magnitude of those events has increased since 2007 in the GBRW due to more pronounced monsoonal conditions, but the Chl increase was not found to be statistically significant. In contrast, the significant decrease in both Chl and TSM in the VDG over the MERIS mission remains unexplained.

MCI and FLH are useful indicators of algal blooms. Surface algal blooms, detected using MCI, were found to occur in both regions (predominantly between August and October). A decrease in the magnitude of those events tends to characterize the GBRW, whilst in the VDG the overall number of 
occurrences of those surface blooms was lower. The large tides and the strong Easterly winds that blow during the dry season do not contribute to stable water column conditions, which may account for a limited occurrence of Trichodesmium $s p$. in the VDG. Finer spatial resolution ocean color sensors may allow the mapping of smaller scale bloom events that remain undetected with the MERIS $1 \mathrm{~km}$ resolution imagery used in this study. Also, the use of FLH may be preferred to assess the Chlorophyll content during surface bloom events, because their near-infrared signatures (red-edge) often lead to Level 2 Chl algorithm failures.

In situ measurements of apparent and inherent optical properties-along with field observations of surface bloom occurrences in the VDG-are required to evaluate the performance of ocean color products in this optically complex region. When applied to other tropical coastal regions, future application of the method should incorporate satellite derived sea surface temperature fields from AATSR and should account for tidal effects in the magnitude of the ocean color products.

\section{Acknowledgments}

For this research, David Blondeau-Patissier was supported by a $\mathrm{PhD}$ scholarship from the International Postgraduate Research Scholarships (The University of Queensland), a top-up scholarship from the Wealth from Oceans (WfO) National Research Flagship Program (CSIRO) and a post-doctoral fellowship from The North Australian Marine Research Alliance (NAMRA). Funding from the Australian Government's National Environmental Research Program (NERP) and the CSIRO Wealth from Ocean (WfO) Flagship to Thomas Schroeder and Vittorio Brando also supported this work. The authors are grateful to Sandra Edgar-Grant (Charles Darwin University) for providing editing support for this manuscript. We would like to thank the European Space Agency (ESA) and the ODESA system (ACRI-ST) for providing the large volume of MERIS satellite images used in this study. We would like to thank the three anonymous reviewers whose comments have largely improved the manuscript.

\section{Author Contributions}

D. Blondeau-Patissier proposed and developed the research design, collected the satellite data, analysed and led the interpretation of the results, and wrote the manuscript with the contribution from all co-authors. T. Schroeder and V. Brando assisted with the data processing, the interpretation of the results and contributed to the study design and manuscript writing. S. Maier, A. Dekker and S. Phinn contributed to the design of the study and the interpretation of the results.

\section{Conflicts of Interest}

The authors declare no conflict of interest.

\section{References}

1. Chiswell, S.M. Annual cycles and spring blooms in phytoplankton: Don't abandon Sverdrup completely. Mar. Ecol. Prog. Ser. 2011, 443, 39-50. 
2. Garcia-Soto, C.; Pingree, R.D. Spring and summer blooms of phytoplankton (SeaWiFS/MODIS) along a ferry line in the Bay of Biscay and Western English Channel. Cont. Shelf Res. 2009, 29, 1111-1122.

3. Furnas, M. Catchments and Corals: Terrestrial Runoff to the Great Barrier Reef; CRC/AIMS: Townsville, Australia, 2003; p. 335.

4. Condie, S.A. Modeling seasonal circulation, upwelling and tidal mixing in the Arafura and Timor seas. Cont. Shelf Res. 2011, 31, 1427-1436.

5. Henson, S.A.; Sarmiento, J.L.; Dunne, J.P.; Bopp, L.; Lima, I.; Doney, S.C.; John, J.; Beaulieu, C. Detection of anthropogenic climate change in satellite records of ocean chlorophyll and productivity. Biogeosciences 2010, 7, 621-640.

6. Done, T.; Jones, R. Tropical Coastal Ecosystems and Climate Change Prediction: Global and Local Risks. In Coral Reefs and Climate Change: Science and Management; Phinney, J.T., Strong, A., Skirving, W., Kleypas, J., Hoegh-Guldberg, H., Eds.; American Geophysical Union: Washington, DC, USA, 2006; pp. 5-32.

7. Burke, L.; Reytar, K.; Spalding, M.; Perry, A. Reefs at Risk Revisited; World Resources Institute: Washington, DC, USA, 2011; p. 114.

8. Waterhouse, J.; Brodie, J.; Lewis, S.; Mitchell, A. Quantifying the sources of pollutants in the Great Barrier Reef catchments and the relative risk to reef ecosystems. Mar. Pollut. Bull. 2012, 65, 394-406.

9. Brodie, J.E.; Kroon, F.J.; Schaffelke, B.; Wolanski, E.C.; Lewis, S.E.; Devlin, M.J.; Bohnet, I.C.; Bainbridge, Z.T.; Waterhouse, J.; Davis, A.M. Terrestrial pollutant runoff to the Great Barrier Reef: An update of issues, priorities and management responses. Mar. Pollut. Bull. 2012, 65, 81-100.

10. Wooldridge, S.A. Water quality and coral bleaching thresholds: Formalising the linkage for the inshore reefs of the Great Barrier Reef, Australia. Mar. Pollut. Bull. 2009, 58, 745-751.

11. Brodie, J.; Schroeder, T.; Rohde, K.; Faithful, J; Masters, B.; Dekker, A.; Brando, V.E.; Maughan, M. Dispersal of suspended sediments and nutrients in the Great Barrier Reef lagoon during river-discharge events: Conclusions from satellite remote sensing and concurrent flood-plume sampling. Mar. Freshw. Res. 2010, 61, 651-664.

12. Brodie, J.E.; Devlin, M.; Haynes, D.; Waterhouse, J. Assessment of the eutrophication status of the Great Barrier Reef Lagoon (Australia). Biogeochemistry 2011, 106, 281-302.

13. Halpern, B.S.; Walbridge, S.; Selkoe, K.A.; Kappel, C.V.; Micheli, F.; D’Agrosa, C.; Bruno, J.F.; Casey, K.S.; Ebert, C.; Fox, H.E.; et al. A global map of human impact on marine ecosystems. Science 2008, 319, 948-952.

14. Hallegraeff, G.M.; Jeffrey, S.W. Tropical phytoplankton species and pigments in continental shelf waters of North and North-West Australia. Mar. Ecol. Prog. Ser. 1984, 20, 59-74.

15. IOCCG. Remote Sensing of Ocean Colour in Coastal, and Other Optically-Complex, Waters: 3; Bedford Institude: Dartmouth, NS, Canada, 2000; p. 145.

16. Odermatt, D.; Gitelson, A.; Brando, V.E.; Schaepman, M. Review of constituent retrieval in optically deep and complex waters from satellite imagery. Remote Sens. Environ. 2012, 118, 116-126.

17. Brando, V.E.; Dekker, A.G.; Park, Y.J.; Schroeder, T. An adaptive semi-analytical inversion of ocean colour radiometry in optically complex waters. Appl. Opt. 2012, 51, 2808-2833. 
18. Matthews, M.W. A current review of empirical procedures of remote sensing in inland and near-coastal transitional waters. Int. J. Remote Sens. 2011, 32, 6855-6899.

19. Sharples, J.; Ross, O.N.; Scott, B.E.; Greenstreet, S.P.R.; Fraser, H. Inter-annual variability in the timing of stratification and the spring bloom in the North-Western North Sea. Cont. Shelf Res. 2006, 26, 733-751.

20. Gower, J.; King, S. An antarctic ice-related "superbloom" observed with the MERIS satellite imager. Geophys. Res. Lett. 2007, 34, doi:10.1029/2007GL029638.

21. Kahru, M.; Brotas, V.; Manzano-Sarabia, M.; Mitchell, B.G. Are phytoplankton blooms occurring earlier in the Arctic? Glob. Chang. Biol. 2010, 17, 1733-1739.

22. Brewin, R.J.W.; Hirata, T.; Hardman-Mountford, N.J.; Lavender, S.J.; Sathyendranath, S.; Barlow, R. The influence of the indian ocean dipole on interannual variations in phytoplankton size structure as revealed by Earth Observation. Deep Sea Res. Part II Top. Stud. Oceanogr. 2012, 77-80, 117-127.

23. Ryan, J.P.; Fischer, A.M.; Kudela, R.M.; Gower, J.; King, S.A.; MarinIIIa, R.; Chavez, F.P. Influences of upwelling and downwelling winds on red tide bloom dynamics in Monterey Bay, California. Cont. Shelf Res. 2009, 29, 785-795.

24. Peñaflor, E.L.; Villanoy, C.L.; Liu, C.-T.; David, L.T. Detection of monsoonal phytoplankton blooms in Luzon Strait with MODIS data. Remote Sens. Environ. 2007, 109, 443-450.

25. Tian, T.; Merico, A.; Su, J.; Staneva, J.; Wiltshire, K.; Wirtz, K. Importance of resuspended sediment dynamics for the phytoplankton spring bloom in a coastal marine ecosystem. J. Sea Res. 2009, 62, 214-228.

26. Blondeau-Patissier, D.; Gower, J.F.R.; Dekker, A.G.; Phinn, S.R.; Brando, V.E. A review of ocean color remote sensing methods and statistical techniques for the detection, mapping and analysis of phytoplankton blooms in coastal and open oceans. Prog. Oceanogr. 2014, in press.

27. Doerffer, R.; Sørensen, K.; Aiken, J. MERIS potential for coastal zone applications. Int. J. Remote Sens. 1999, 20, 1809-1818.

28. MERIS Quality Working Group. MERIS 3rd Data Reprocessing-Software and ADF Updates; MERIS Quality Working Group: Nice, France, 2011; p. 84.

29. Steinmetz, F.; Deschamps, P.Y.; Ramon, D. Atmospheric correction in presence of sun glint: Application to MERIS. Opt. Express 2011, 19, 9783-9800.

30. Gower, J.; Doerffer, R.; Borstad, G.A. Interpretation of the $685 \mathrm{~nm}$ peak in water-leaving radiance spectra in terms of fluorescence, absorption and scattering, and its observation by MERIS. Int. J. Remote Sens. 1999, 20, 1771-1786.

31. Gower, J.; King, S.; Goncalves, P. Global monitoring of plankton blooms using MERIS MCI. Int. J. Remote Sens. 2008, 29, doi:10.1080/01431160802178110.

32. Schroeder, T.; Behnert, I.; Schaale, M.; Fischer, J.; Doerffer, R. Atmospheric correction algorithm for MERIS above case-2 waters. Int. J. Remote Sens. 2007, 28, 1469-1486.

33. Fomferra, N.; Brockmann, C. Beam-The ENVISAT MERIS and AATSR Toolbox. In Proceedings of the MERIS-(A)ATSR Workshop, Frascati, Italy, 26-30 September 2005; p. 3.

34. Schroeder, T.; Schaale, M.; Fisher, J. Retrieval of atmospheric and oceanic properties from meris measurements: A new Case-2 water processor for BEAM. Int. J. Remote Sens. 2007, 28, 5627-5632. 
35. Blondeau-Patissier, D. Detection and Quantification of Algal Bloom Dynamics in the Great Barrier Reef Lagoonal Waters Using Remote Sensing and Bio-Optics. Ph.D. Thesis, University Of Queensland, Brisbane, Australia, 2011.

36. Binding, C.E.; Greenberg, T.A.; Bukata, R.P. The MERIS maximum chlorophyll index; its merits and limitations for inland water algal bloom monitoring. J. Great Lakes Res. 2013, 39, 100-107.

37. Gower, J.; King, S.A. Distribution of floating Sargassum in the Gulf of Mexico and the Atlantic ocean mapped using MERIS. Int. J. Remote Sens. 2011, 32, 1917-1929.

38. Montes-Hugo, M.A.; Fiorani, L.; Marullo, S.; Roy, S.; Gagné, J.-P.; Borelli, R.; Demers, S.; Palucci, A. A comparison between local and global spaceborne Chlorophyll indices in the St. Lawrence estuary. Remote Sens. 2012, 4, 3666-3688.

39. Wynne, T.T.; Stumpf, R.P.; Tomlinson, M.C.; Warner, R.A.; Tester, P.A.; Dyble, J.; Fahnenstiel, G.L. Relating spectral shape to Cyanobacterial blooms in the Laurentian Great Lakes. Int. J. Remote Sens. 2008, 29, 3665-3672.

40. Wynne, T.T.; Stumpf, R.P.; Briggs, T.O. Comparing MODIS and MERIS spectral shapes for Cyanobacterial bloom detection. Int. J. Remote Sens. 2013, 34, 6668-6678.

41. Schroeder, T.; Devlin, M.J.; Brando, V.E.; Dekker, A.G.; Brodie, J.E.; Clementson, L.A.; McKinna, L. Inter-annual variability of wet season freshwater plume extent into the Great Barrier Reef Lagoon based on satellite coastal ocean colour observations. Mar. Pollut. Bull. 2012, 65, 210-223.

42. Susanto, R.D.; Moore, T.S.; Marra, J. Ocean color variability in the Indonesian Seas during the SeaWiFS era. Geochem. Geophys. Geosyst. 2006, 7, doi:10.1029/2005GC001009.

43. Andrews, J.C.; Clegg, S. Coral sea circulation and transport deduced from modal information models. Deep Sea Res. Part A Oceanogr. Res. Pap. 1989, 36, 957-974.

44. Schaffelke, B.; Carleton, J.; Skuza, M.; Zagorskis, I.; Furnas, M.J. Water quality in the inshore Great Barrier Reef lagoon: Implications for long-term monitoring and management. Mar. Pollut. Bull. 2012, 65, 249-260.

45. Neil, D.T.; Orpin, A.; Vid, P.; Yu, B. Sediment yield and impacts from river catchments to the Great Barrier Reef lagoon. Mar. Freshw. Res. 2002, 53, 733-752.

46. King, B.; Wolanski, E. Bottom Friction Reduction in Turbid Estuaries. In Mixing in Estuaries and Coastal Seas; Pattiaratchi, C., Ed.; AGU: Washington, DC, USA, 1996; Volume 50, pp. 325-337.

47. Furnas, M.J.; Mitchell, A.W. Biological Oceanography of the Great Barrier Reef. In The Great Barrier Reef: Science, Use and Management; Great Barrier Reef Marine Park Authority: Townsville, Queensland, Australia, 1997; pp. 75-81.

48. Furnas, M. Net in situ growth rates of phytoplankton in an oligotrophic, tropical shelf ecosystem. Limnol. Oceanogr. 1991, 36, 13-29.

49. Blondeau-Patissier, D.; Brando, V.E.; Oubelkheir, K.; Dekker, A.G.; Clementson, L.A.; Daniel, P. Bio-optical variability of the absorption and scattering properties of the Queensland inshore and reef waters, Australia. J. Geophys. Res. 2009, 114, doi:10.1029/2008JC005039.

50. Wooldridge, S.; Brodie, J.; Furnas, M. Exposure of inner-shelf reefs to nutrient enriched runoff entering the Great Barrier Reef Lagoon: Post-european changes and the design of water quality targets. Mar. Pollut. Bull. 2006, 52, 1467-1479.

51. Sorokin, Y.I.; Sorokin, P. Plankton of the central Great Barrier Reef: Abundance, production and trophodynamic roles. J. Mar. Biol. Assoc. UK 2010, 90, 1173-1187. 
52. Crosbie, N.D.; Furnas, M.J. Abundance, distribution and flow-cytometric characterization of picophytoprokaryote populations in central $\left(17^{\circ} \mathrm{S}\right)$ and southern $\left(20^{\circ} \mathrm{S}\right)$ shelf waters of the Great Barrier Reef. J. Plankton Res. 2001, 23, 809-828.

53. McKinna, L.I.W.; Furnas, M.J.; Ridd, P.V. A simple, binary classification algorithm for the detection of Trichodesmium spp. within the Great Barrier Reef using MODIS imagery. Limnol. Oceanogr. Methods 2011, 9, 50-66.

54. Drewry, J.; Dostine, P.L.; Fortune, J.; Majid, M.; Schult, J.; Lamche, G. Darwin Harbour Region Report Cards 2010; 25/2010D; Department of Natural Resources, Environment, The Arts and Sport: Palmerston, Northern Territory, Australia, 2010; p. 74.

55. Blondeau-Patissier, D.; Dekker, A.G.; Schroeder, T.; Brando, V.E. Thematic Findings: Surface Phytoplankton Blooms and Phytoplankton Biomass in Coastal Waters. In Australia State of the Environment 2011. Independent Report to the Australian Government Minister for Sustainability, Environment, Water, Population and Communities; DSEWPaC: Canberra, Australia, 2011; pp. 410-411.

56. Ferreira, A.; Garcia, C.A.E.; Dogliotti, A.I.; Garcia, V.M.T. Bio-optical characteristics of the Patagonia shelf break waters: Implications for ocean color algorithms. Remote Sens. Environ. 2013, 136, 416-432.

57. IOCCG. Partition of the Ocean into Ecological Provinces: Role of Ocean-Colour Radiometry; Report number 9; Bedford Institude: Dartmouth, NS, Canada, 2009.

58. Jassby, A.D.; Cloern, J.E. Package “wq"-Some Tools for Exploring Water Quality Monitoring Data, Version 0.3-4; R-CRAN, R Foundation for Statistical Computing: Vienna, Austria, 2011.

59. Team, R.C. R: A Language and Environment for Statistical Computing; R Foundation for Statistical Computing: Vienna, Austria, 2013.

60. Hirsch, R.M.; Slack, J.R.; Smith, R.A. Techniques of trend analysis formonthly water quality data. Water Resour. Res. 1982, 18, 107-121.

61. Brodie, J.; Wolanski, E.; Lewis, S.; Bainbridge, Z. An assessment of residence times of land-sourced contaminants in the Great Barrier Reef Lagoon and the implications for management and reef recovery. Mar. Pollut. Bull. 2012, 65, 267-279.

62. Weeks, S.; Werdell, P.J.; Schaffelke, B.; Canto, M.; Lee, Z.; Wilding, J.G.; Feldman, G.C. Satellite-derived photic depth on the great barrier reef: Spatio-temporal patterns of water clarity. Remote Sens. 2012, 4, 3781-3795.

63. Brodie, J.; De'ath, G.; Devlin, M.; Furnas, M.; Wright, M. Spatial and temporal patterns of near-surface chlorophyll a in the Great Barrier Reef lagoon. Mar. Freshw. Res. 2007, 58, 342-353.

64. Brinkman, R.; Wolanski, E.; Deleersnijderb, E.; McAllistera, F.; Skirvinga, W. Oceanic inflow from the coral sea into the Great Barrier Reef. Estuar. Coast. Shelf Sci. 2001, 54, 655-668.

65. Hancock, G.J.; Webster, I.T.; Stieglitz, T.C. Horizontal mixing of Great Barrier Reef waters: Offshore diffusivity determined from radium isotope distribution. J. Geophys. Res. 2006, 111, doi:10.1029/2006JC003608.

66. Gower, J.; King, S.; Borstad, G.; Brown, L. The importance of a band at $709 \mathrm{~nm}$ for interpreting water-leaving spectral radiance. Can. J. Remote Sens. 2008, 34, 287-295. 
67. Devlin, M.J.; Brodie, J.E.; Bainbridge, Z.T.; Lewis, S.E. Flood Plumes in the Great Barrier Reef-the Burdekin and Fitzroy Flood Plumes (2007/08): Case Studies for Marine Monitoring Program; James Cook University: Townsville, Australia, 2008; p. 63.

68. Lyon, P.; Acker, J.; Hoge, F.; Shen, S.; Roffer, M.; Gawlikowski, G. Interaction of Hurricane Katrina with Optically Complex Water in the Gulf of Mexico: Interpretation Using Satellite-Derived Inherent Optical Properties and Chlorophyll Concentration. In Proceedings of the 2008 Fall Meeting of the American Geophysical Union, San Francisco, CA, USA, 15-19 December 2008.

69. Acker, J.; Lyon, P.; Hoge, F.; Shen, S.; Roffer, M.; Gawlikowski, G. Interaction of Hurricane Katrina with optically complex water in the Gulf of Mexico: Interpretation using satellite-derived inherent optical properties and chlorophyll concentration. IEEE Geosci. Remote Sens. Lett. 2009, 6, 209-213.

70. Neveux, J.; Tenório, M.M.B.; Jacquet, S.; Torreton, J.P.; Douillet, P.; Ouillon, S.; Dupouy, C. Chlorophylls and phycoerythrins as markers of environmental forcings including cyclone Erica effect (March 2003) on phytoplankton in the south-west Lagoon of New Caledonia and oceanic adjacent area. Int. J. Oceanogr. 2009, 2009, 1-19.

71. Shi, W.; Wang, M. Observations of a Hurricane Katrina-induced phytoplankton bloom in the Gulf of Mexico. Geophys. Res. Lett. 2007, 34, doi:10.1029/2007GL029724.

72. Campbell, D.; Hurry, V.; Clarke, A.K.; Gustafsson, P.; Oquist, G. Chlorophyll fluorescence analysis of Cyanobacterial photosynthesis and acclimation. Microbiol. Mol. Biol. Rev. 1998, 62, 667-683.

73. Qu, T.; Du, Y.; Strachan, J.; Meyers, G.; Slingo, J. Sea surface temperature and its variability in the Indonesian region. Oceanography 2005, 18, 50-61.

74. Huisman, J.; Hulot, F.D. Population Dynamics of Harmful Cyanobacteria. In Harmful Cyanobacteria; Huisman, J., Matthijs, H.C.P., Visser, M., Eds.; Springer: Dordrecht, the Netherlands, 2005; pp. 143-176.

75. $\mathrm{Fu}, \mathrm{F} . \mathrm{X}$.; Bell, P.R.F. Effect of salinity on growth, pigmentation, $\mathrm{N}_{2}$ fixation and alkaline phosphatase activity of cultured Trichodesmium sp. Mar. Ecol. Prog. Ser. 2003, 257, 69-76.

76. Gazeau, F.; Smith, S.V.; Gentili, B.; Frankignoulle, M.; Gattuso, J.-P. The European coastal zone: Characterization and first assessment of ecosystem metabolism. Estuar. Coast. Shelf Sci. 2004, 60, 673-694.

77. Siegel, D.A.; Antoine, D.; Behrenfeld, M.J.; Fanton d'Andon, O.H.; Fields, E.; Franz, B.A.; Goryl, P.; Maritorena, S.; McClain, C.R.; Wang, M.; et al. Global Ocean Phytoplankton. In State of the Climate in 2010, Bulletin of the American Meteorological Society; AMS: Boston, MA, USA, 2011; Volume 93, pp. S107-S110.

(C) 2014 by the authors; licensee MDPI, Basel, Switzerland. This article is an open access article distributed under the terms and conditions of the Creative Commons Attribution license (http://creativecommons.org/licenses/by/3.0/). 